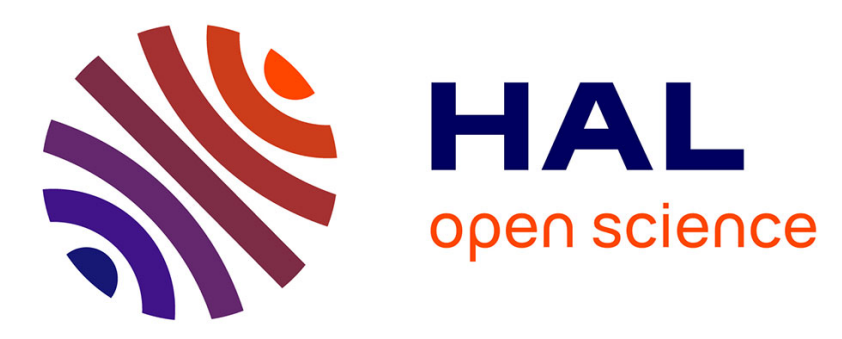

\title{
A comparison of displacement-based Timoshenko multi-fiber beams finite element formulations and elasto-plastic applications
}

Ibrahim Bitar, Stéphane Grange, Panagiotis Kotronis, Nathan Benkemoun

\section{To cite this version:}

Ibrahim Bitar, Stéphane Grange, Panagiotis Kotronis, Nathan Benkemoun. A comparison of displacement-based Timoshenko multi-fiber beams finite element formulations and elasto-plastic applications. European Journal of Environmental and Civil Engineering, 2018, 22 (4), pp.464 - 490. 10.1080/19648189.2016.1210031 . hal-01716706

\section{HAL Id: hal-01716706 \\ https://hal.science/hal-01716706}

Submitted on 22 Oct 2019

HAL is a multi-disciplinary open access archive for the deposit and dissemination of scientific research documents, whether they are published or not. The documents may come from teaching and research institutions in France or abroad, or from public or private research centers.
L'archive ouverte pluridisciplinaire HAL, est destinée au dépôt et à la diffusion de documents scientifiques de niveau recherche, publiés ou non, émanant des établissements d'enseignement et de recherche français ou étrangers, des laboratoires publics ou privés. 


\title{
A comparison of displacement-based Timoshenko multi-fiber beams finite element formulations and elasto-plastic applications
}

\author{
Ibrahim Bitar $^{\mathrm{a} *}$, Stéphane Grange ${ }^{\mathrm{b}}$, Panagiotis Kotronis ${ }^{\mathrm{a}}$ and Nathan Benkemoun ${ }^{\mathrm{c}}$ \\ ${ }^{a}$ École Centrale de Nantes, Université de Nantes, CNRS Institut de Recherche en Génie Civil et \\ Mécanique (GeM), UMR 6183, 1 rue de la Noë, BP 92101, Nantes, cedex 3, France; ${ }^{b}$ Université \\ Grenoble Alpes, CNRS, 3SR, Grenoble, France; ${ }^{c} I U T$ Saint-Nazaire, Université de Nantes, CNRS \\ Institut de Recherche en Génie Civil et Mécanique (GeM), UMR 618358 rue Michel Ange, Saint- \\ Nazaire, France
}

\begin{abstract}
Various formulations of displacement-based Timoshenko multi-fiber beams are compared in this article. After a short literature review, the presentation of the shape functions leading to the stiffness matrices and the consistent nodal forces relative to each formulation are presented and their performances are studied using elastic or elastic perfectly plastic constitutive laws and simple to complex static loadings. The advantages and disadvantages of each formulation are highlighted and general conclusions are drawn on the use of displacement-based Timoshenko multi-fiber beams in engineering. An innovative solution is finally proposed to improve the performance for the case of axialbending interactions.
\end{abstract}

Keywords: Timoshenko; multi-fiber; displacement-based beam; shape functions

\section{Introduction}

The modelling of engineering structural elements is often made using two approaches: mesoscopic (stress-strain) 2D or 3D finite element models able to capture local phenomena such as crack initiation and propagation, bond slip and aggregate interlocking (e.g. reinforced concrete beams); and global scale models (e.g. beam, plates or shell elements) where specific kinematic assumptions are adopted to simplify the global equilibrium equations and to reduce the required number of degrees of freedom.

The classical Timoshenko beam theory adopts the kinematic assumption that plane sections remain plane but not necessarily normal to the beam axis. It is often used because it can (approximately) take into account the influence of shear strains and stresses. On the contrary, the Euler-Bernoulli theory (sections remain plane and normal to the beam axis) neglects their influence and provides therefore satisfactory results for the case of slender beam structures only. Euler-Bernoulli or Timoshenko beam finite elements are either displacement-based (stiffness approach, see for example Nickel \& Secor, 1972; Tessler \& Dong, 1981; Thomas \& Abbas, 1975) or force-based (flexibility approach, see for example Saritas \& Filippou, 2009; Spacone, Filippou, \& Taucer, 1996).

For non linear calculations, Euler-Bernoulli and Timoshenko beam finite element beams are divided in two categories: lumped beams where the material non linearity is concentrated at the element's ends; and distributed models where the inelastic deformations can spread

\footnotetext{
*Corresponding author. Email: ibrahim.bitar@ec-nantes.fr
} 
along the element. Considering the sectional behaviour, one can distinguish the stress resultant (e.g. moment - rotation) models (Bui, Ngo, Nikolic, Brancherie, \& Ibrahimbegovic, 2014; Dujc, Brank, \& Ibrahimbegovic, 2010; Jukic et al., 2013; Pham et al., 2010) and multi-fiber beams, where the beam section is divided in "fibers" associated with a local strain-stress constitutive law.

During the last 20 years, various multi-fiber beam elements have been developed and implemented in research and commercial oriented finite element codes. One of the first manuscripts introducing the idea of dividing a beam section in "fibers" with a specific stress/strain relation is the book of Owen and Hinton (1980), followed by the works of Chan (1983), Izzuddin (1990), Scordelis (1984), Spacone et al. (1996). Multi-fiber beams have been proven very efficient for various applications in civil engineering: the non linear analysis of beam type or bearing wall structures with non homogeneous sections (e.g. reinforced concrete) (Grange et al., 2009; Ile et al., 2008; Kotronis \& Mazars, 2005; Kotronis et al., 2005), arbitrarily geometrical plane or hollow shape sections (Desprez, Kotronis, \& Mazars, 2014; Grange, Botrugno, Kotronis, \& Tamagnini, 2011) submitted to flexion, shear or torsion (Mazars, Kotronis, Ragueneau, \& Casaux, 2006), axial and flexure interactions (Chan, 1983; Izzuddin, 1990; Pinho \& Elnashai, 2000; Scordelis, 1984; Spacone \& Limkatanyu, 2000), soil structure interaction (Grange et al., 2011), vulnerability assessment (Desprez et al., 2014) and fiber-reinforced polymer retrofitting (Desprez, Mazars, Kotronis, \& Paultre, 2013).

The Euler-Bernoulli multi-fiber beams are used for cases where shear effects are not significant (Spacone \& Limkatanyu, 2000). They fail therefore to account for axial, shear and flexure interactions. This is the reason why Timoshenko multi-fiber beams have been also developed: (Bairan Garcia \& Mari Bernat, 2006; Caillerie, Kotronis, \& Cybulski, 2015; Jukić, Brank, \& Ibrahimbegović, 2014; Kotronis \& Mazars, 2005; Mazars et al., 2006; Marini \& Spacone, 2006; Navarro Gregori et al., 2007; Petrangeli et al., 1999; Ranzo \& Petrangeli, 1988; Šćulac et al., 2014). One has to keep in mind however that Timoshenko multi-fiber beams are unable to capture the real behaviour of structures with very small slenderness since the latter no longer behaves like a beam (see Mazars, Kotronis, \& Davenne, 2002). For these cases, 2D or 3D finite element models (Ile \& Reynouard, 2000) or other adequate simplified modelling strategies should be preferred (Mazars et al., 2002).

Another important aspect concerns the material constitutive behaviour adopted in the context of multi-fiber beams. Different choices can be found in the literature: damage models (see for example Kotronis \& Mazars, 2005), plasticity models (Dujc et al., 2010), coupled plasticity and damage models (Ibrahimbegović et al., 2007), simplified models for confined concrete columns (Desprez et al., 2013) or approaches based on the modified compression field theory introduced by Vecchio and Collins $(1986,1988)$.

The main purpose of the article being the influence of the different shape functions interpolating the displacement field on the element response, we focus hereafter on displacement based Timoshenko multi-fiber beams with simple uniaxial linear elastic or elasto-plastic constitutive laws. The shear strains are constant in the beam section, the shear stresses are supposed linear elastic and are multiplied by the classical shear correction factor $k$ (Bathe, 2006; Cowper, 1966). Force-based beam elements - see for example (Ciampi \& Carlesimo, 1986 and Spacone et al., 1996) - are out of the scope of the article. Furthermore, non linear axial, shear and flexure interactions are not specifically addressed, the interested readers can among others refer to Bui et al. (2014), Ceresa et al. (2007), Ceresa, Petrini, Pinho, \& Sousa (2009, Saritas and Filippou (2009), Xu and Zhang (2012), Zona and Ranzi (2011)).

In the following, we present and compare the performance of three (3) displacementbased straight Timoshenko multi-fiber beam finite elements under the small rotations 
assumption. The formulations differ on the shape functions interpolating the displacements and rotations fields. The first formulation, called hereafter (Full-Linear-Independent) FLI, adopts linear polynomials while the transverse displacements and rotation fields are interpolated independently, see (Guedes, Pegon, \& Pinto, 1994 and Pegon, 1994). Because of the low degree of the adopted polynomials, this formulation is prone to shear locking problems (see Beirão da Veiga et al., 2012; Ceresa et al., 2009; Crisfield, 1991; De Ville de Goyet, 1989; Ibrahimbegović \& Frey, 1993; Mukherjee et al., 2001; Rakowski, 1990; Reddy, 1997; Stolarski \& Belytschko, 1982 and Yunhua, 1998) if specific measures are not considered. A way to avoid this is to calculate the shear strains approximately, as proposed by Donea and Lamain (1987) and adopted in Guedes et al. (1994) and Pegon (1994). In the second formulation, referred hereafter as (Full-Cubic-Quadratic-Material) FCQM, proposed by Friedman and Kosmatka (1993) for Timoshenko beams (further bibliography on Timoshenko beam finite elements can be found in Kiendl et al. (2015), Litewka and Rakowski (1998), Nickel and Secor (1972), Papa Dukic et al. (2014), Tessler and Dong (1981) and Thomas and Abbas (1975) and adopted in Kotronis and Mazars (2005) and Mazars et al. (2006) in a multi-fiber context, the degree of the shape functions is of order three (3) for the transverse displacements and two (2) for the rotations. Displacements and rotations are now interdependent and the shear locking problem is avoided. The particularity of this formulation is that the shape functions depend on material properties, and therefore their use for non linear problems can be problematic. The third formulation, called hereafter (Full-Cubic-Quadratic) FCQ, is proposed by Caillerie et al. (2015) and uses shape functions of order three (3) for the transverse displacements and two (2) for the rotations and an additional internal node. This results to a finite element free of shear locking and to shape functions independent on the material properties. The choice to compare these formulations is motivated by the fact that the first two elements FLI and FCQM are implemented, respectively, in the general purpose finite element codes (Aster, Retrieved from http:// code-aster.org/ and Castem, Retrieved from http://www-cast3m.cea.fr/). The more recent FCQ element is chosen in order to study its performance.

The article is organised as follows: in the first section, the main equations of the Timoshenko beam theory are recalled as well as the general form of the displacement and strain fields, the stiffness matrices and the consistent nodal force vectors within a multifiber beam approach. In the second section, the specific equations for the FLI, FCQM and FCQ formulations are provided. The performance of each formulation is studied in the third section considering an elastic or elasto-plastic behaviour and monotonic loadings. Of particular interest is the last example where we study the specific case of non linear axial-bending interactions. Shape functions of order three (3) are proposed for the axial displacements of the FCQ element in order to increase its accuracy (Section 4.5.1). The article ends with general conclusions and guidelines.

\section{Timoshenko multi-fiber beams}

\subsection{Kinematic assumptions}

Consider the case of a 2D straight beam, with a length $€$ and a normal cross-section $S(x)$, its middle axis $\Delta=(0, \mathrm{t})$ oriented towards the $x$ direction. The small rotations hypothesis is adopted and the classical Timoshenko assumptions are made (the cross-section $S(x)$ remains plane but not necessary orthogonal to the deformed middle axis). The generalised displacements vector $U(x)$ of the cross-section $S(x)-G(x, 0)$ being a point of the section $S(x)$ on the middle axis, see Figure 1 - takes the following form (in the following, the upper index $T$ states for "transpose", the term "generalised" and the capital symbols $U$ and $\Theta$ 

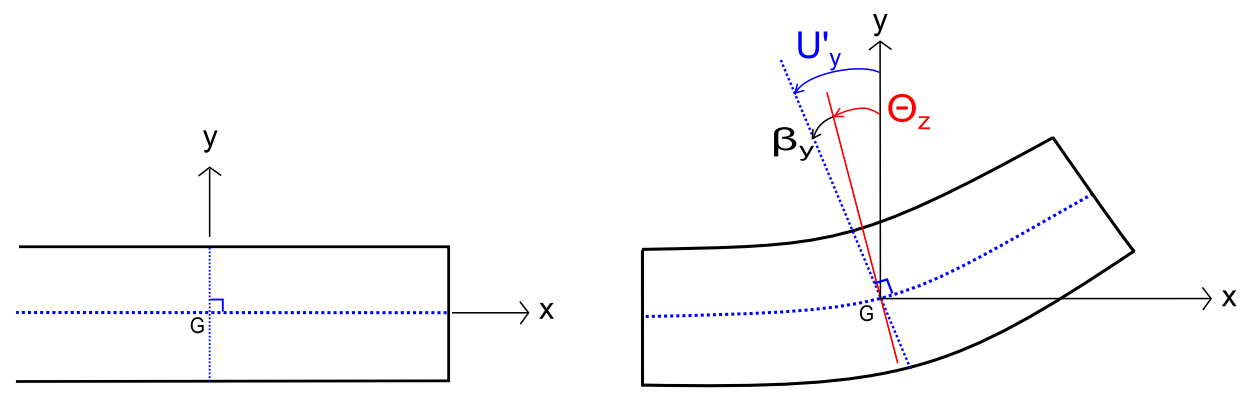

Figure 1. Kinematics of a Timoshenko beam.

refer to the section):

$$
U(x)=\left[U_{x}(x) U_{y}(x) \Theta_{z}(x)\right]^{T}
$$

$U_{x}(x)$ being the longitudinal displacement, $U_{y}(x)$ the transverse displacement and $\Theta_{z}(x)$ the rotation of the section $S(x)$ where the point $G(x, 0)$ is situated (see Figure 1). The displacements $u_{x}(x, y), u_{y}(x, y)$ of another point $P(x, y)$ of the section $S(x)$ (or of a "fiber" $f(x, y))$ are evaluated using the section displacements as follows:

$$
\begin{aligned}
& u_{x}(x, y)=U_{x}(x)-y \Theta_{z}(x), \\
& u_{y}(x, y)=U_{y}(x)
\end{aligned}
$$

The strain field becomes (the symbol' defines hereafter the derivative with respect to $x$ ):

$$
\begin{aligned}
\varepsilon_{x}(x, y) & =\frac{\partial u_{x}}{\partial x}=U_{x}^{\prime}(x)-y \Theta_{z}^{\prime}(x), \\
\gamma_{x y}(x, y) & =\frac{\partial u_{x}}{\partial y}+\frac{\partial u_{y}}{\partial x}=U_{y}^{\prime}(x)-\Theta_{z}(x)=\beta_{y}(x)
\end{aligned}
$$

with $\varepsilon_{x}(x, y)$ the axial strain and $\gamma_{x y}(x, y)$ the transverse shear strain of the fiber $f(x, y)$.

\subsection{Constitutive laws}

At each fiber $f(x, y)$ of the section $S(x)$ a constitutive law can be adopted (e.g. based on elasticity, on damage mechanics or plasticity) linking the axial and the shear terms. For the case of an isotropic elastic material, it takes the following form:

$$
\begin{aligned}
& \sigma_{x}(x, y)=E_{f}(x, y) \varepsilon_{x}(x, y), \\
& \tau_{x y}(x, y)=k G_{f}(x, y) \gamma_{x y}(x, y)
\end{aligned}
$$

where $E_{f}(x, y)$ and $G_{f}(x, y)$ are the Young and the Shear modulus, respectively, and $k$ is the shear correction factor adopted in Timoshenko beam finite elements (due to the fact that the resulting shear stresses do not respect the boundary conditions on the beam section Bathe, 2006; Cowper, 1966). The values of the shear correction factor for different crosssectional shapes can be found in Cowper (1966). A discussion on the shear correction factors can be also found in Dong et al. (2010).

In the following and for sake of clarity and simplicity the dependencies on $x$ or $x, y$ are omitted. 


\subsection{Virtual work principle}

The virtual work principle becomes Guedes et al. (1994) and Pegon (1994):

$$
\int_{0}^{€} \int_{S}\left(\delta \varepsilon_{x} \sigma_{x}+\delta \gamma_{x y} \tau_{x y}\right) \mathrm{d} S \mathrm{~d} x-w_{\text {external }}=0
$$

where the first term is related to the work of the internal loadings and $w_{\text {external }}$ the work of the external loadings.

Introducing (3) in (5), yields

$$
\int_{0}^{\mathrm{E}} \int_{S}\left(\delta\left(U_{x}^{\prime}-y \Theta_{z}^{\prime}\right) \sigma_{x}+\left(\delta U_{y}^{\prime}-\delta \Theta_{z}\right) \tau_{x y} \mathrm{~d} S \mathrm{~d} x-w_{\text {external }}=0\right.
$$

where $\delta U_{x}$ is the virtual axial displacement, $\delta U_{y}$ the virtual transversal displacement and $\delta \Theta_{z}$ the virtual rotation.

The following definitions are adopted for the generalised forces:

$$
F_{x}=\int_{S} \sigma_{x} \mathrm{~d} S, F_{y}=\int_{S} \tau_{x y} \mathrm{~d} S, M_{z}=-\int_{S} y \sigma_{x} \mathrm{~d} S
$$

Axial force Shear force Bending moment

introducing them in (6) one obtains:

$$
\int_{0}^{€}\left(F_{x} \frac{\mathrm{d}}{\mathrm{d} x} \delta U_{x}+F_{y} \frac{\mathrm{d}}{\mathrm{d} x} \delta \beta_{y}+M_{z} \frac{\mathrm{d}}{\mathrm{d} x} \delta \Theta_{z}\right) \mathrm{d} x-w_{\text {external }}=0
$$

where

$$
\beta_{y}=\frac{\mathrm{d} U_{y}}{\mathrm{~d} x}-\Theta_{z}=U_{y}^{\prime}-\Theta_{z}
$$

Considering (3),(4) and (7) gives:

$$
\begin{aligned}
F_{x} & =\int_{S} \sigma_{x} \mathrm{~d} S=\int_{S} E_{f} \varepsilon_{x} \mathrm{~d} S=\int_{S} E_{f}\left(\frac{\mathrm{d} U_{x}}{\mathrm{~d} x}-y \frac{\mathrm{d} \Theta_{z}}{\mathrm{~d} x}\right) \mathrm{d} S=\int_{S} E_{f} \mathrm{~d} S U_{x}^{\prime}-\int_{S} E_{f} y \mathrm{~d} S \Theta_{z}^{\prime} \\
F_{y} & =\int_{S} \tau_{x y} \mathrm{~d} S=\int_{S} k G_{f} \gamma_{x y} \mathrm{~d} S=\int_{S} k G_{f}\left(\beta_{y}\right) \mathrm{d} S=\int_{S} k G_{f} \mathrm{~d} S \beta_{y} \\
M_{z} & =-\int_{S} y \sigma_{x} \mathrm{~d} S=-\int_{S} y E_{f} \varepsilon_{x} \mathrm{~d} S=-\int_{S} y E_{f}\left(\frac{\mathrm{d} U_{x}}{\mathrm{~d} x}-y \frac{\mathrm{d} \Theta_{z}}{\mathrm{~d} x}\right) \mathrm{d} S \\
& =-\int_{S} E_{f} y \mathrm{~d} S U_{x}^{\prime}+\int_{S} E_{f} y^{2} \mathrm{~d} S \Theta_{z}^{\prime}
\end{aligned}
$$

and the generalised force vector $F_{S}$ of the section can be written as:

$$
\underbrace{\left[\begin{array}{c}
F_{x} \\
F_{y} \\
M_{z}
\end{array}\right]}_{F_{S}}=\underbrace{\left[\begin{array}{ccc}
\int_{S} E_{f} \mathrm{~d} S & 0 & -\int_{S} E_{f} y \mathrm{~d} S \\
0 & \int_{S} k G_{f} \mathrm{~d} S & 0 \\
-\int_{S} E_{f} y \mathrm{~d} S & 0 & \int_{S} E_{f} y^{2} \mathrm{~d} S
\end{array}\right]}_{K_{S}} \cdot\left[\begin{array}{c}
U_{x}^{\prime} \\
\beta_{y} \\
\Theta_{z}^{\prime}
\end{array}\right]=K_{S} \cdot\left[\begin{array}{c}
U_{x}^{\prime} \\
\beta_{y} \\
\Theta_{z}^{\prime}
\end{array}\right],
$$

where $U_{x}^{\prime}, \beta_{y}, \Theta_{z}^{\prime}$ are the generalised strains and $K_{S}$ is the multi-fiber section stiffness matrix, independent of the neutral axis position (Guedes et al., 1994).

Finally, considering (8) and (11), one gets for the virtual work principle:

$$
\int_{0}^{€} \delta\left[\begin{array}{lll}
U_{x}^{\prime} & \beta_{y} & \Theta_{z}^{\prime}
\end{array}\right] K_{S}\left[\begin{array}{lll}
U_{x}^{\prime} & \beta_{y} & \Theta_{z}^{\prime}
\end{array}\right]^{T} \mathrm{~d} x-w_{\text {external }}=0
$$


The extension of the previous equations in $3 \mathrm{D}$ is straightforward and follows the same steps (Guedes et al., 1994).

\subsection{Finite element discretisation}

The beam of length $€$ is discretised into $n$ finite element beams $e=\left[x_{i} ; x_{j}\right]$ of length $L_{e}=$ $x_{j}-x_{i}$ and external nodes $i$ and $j$. The generalised displacement vector is approximated by an equation of the form $U=\mathrm{NU}_{e}$ as follows:

$$
\left[\begin{array}{c}
U_{x} \\
U_{y} \\
\Theta_{z}
\end{array}\right]=\left[\begin{array}{cccccc}
N_{1} & N_{2} & N_{3} & N_{4} & N_{5} & N_{6} \\
N_{7} & N_{8} & N_{9} & N_{10} & N_{11} & N_{12} \\
N_{13} & N_{14} & N_{15} & N_{16} & N_{17} & N_{18}
\end{array}\right]\left[\begin{array}{c}
U_{x i} \\
U_{y i} \\
\Theta_{z i} \\
U_{x j} \\
U_{y j} \\
\Theta_{z j}
\end{array}\right]
$$

where $U_{e}$ is a vector containing the external nodal displacements of the element $e$ and $N$ is the matrix of the shape functions depending on $x$.

The generalised strains are evaluated as:

$$
\left[\begin{array}{c}
U_{x}^{\prime} \\
\beta_{y} \\
\Theta_{z}^{\prime}
\end{array}\right]=\left[\begin{array}{c}
U_{x}^{\prime} \\
U_{y}^{\prime}-\Theta_{z} \\
\Theta_{z}^{\prime}
\end{array}\right]=\left[\begin{array}{cccccc}
B_{1} & B_{2} & B_{3} & B_{4} & B_{5} & B_{6} \\
B_{7} & B_{8} & B_{9} & B_{10} & B_{11} & B_{12} \\
B_{13} & B_{14} & B_{15} & B_{16} & B_{17} & B_{18}
\end{array}\right]\left[\begin{array}{c}
U_{x i} \\
U_{y i} \\
\Theta_{z i} \\
U_{x j} \\
U_{y j} \\
\Theta_{z j}
\end{array}\right]=\left[\begin{array}{c}
B_{\text {axial }} \\
B_{\text {shear }} \\
B_{\text {flexion }}
\end{array}\right]\left[\begin{array}{c}
U_{x i} \\
U_{y i} \\
\Theta_{z i} \\
U_{x j} \\
U_{y j} \\
\Theta_{z j}
\end{array}\right],
$$

where $B$ is a matrix containing the derivatives with respect to $x$ of the shape functions.

Introducing (14) in the virtual work expression (12) provides the expression of the stiffness matrix $K_{\text {element }}$ of the element $e$ (Guedes et al., 1994):

$$
K_{\text {element }}=\int_{0}^{L_{e}} B^{T} K_{S} B \mathrm{~d} x
$$

while the assembly of the latter gives the total stiffness matrix of the beam structure:

$$
K_{\mathrm{tot}}=A_{e=1}^{n} \int_{0}^{L_{e}} B^{T} K_{S} B \mathrm{~d} x
$$

The calculation of the internal nodal forces due to a state of (internal) stresses follows the same procedure:

$$
F_{\text {int, element }}=\int_{0}^{L_{e}} B^{T} F_{S} \mathrm{~d} x \Longrightarrow F_{\text {int, tot }}=A_{e=1}^{n} \int_{0}^{L_{e}} B^{T} F_{S} \mathrm{~d} x
$$

The consistent nodal force vector of the finite element beam $e$ due to a distributed vertical load $p(x)$ (Figure 2), is again evaluated using the virtual work principle. The external virtual work in (12) for one (1) element $e$ takes the following form:

$$
\begin{aligned}
w_{\text {external }} & =\int_{0}^{L_{e}} \delta U_{y}(x) p(x) \mathrm{d} x=\int_{0}^{L_{e}} \delta\left(N_{\text {shear }} U_{e}\right)^{T} p(x) \mathrm{d} x=\delta U_{e}^{T} \int_{0}^{L_{e}} N_{\text {shear }}^{T} p(x) \mathrm{d} x \\
& =\delta U_{e}^{T} \times F_{\text {ext, element }}
\end{aligned}
$$




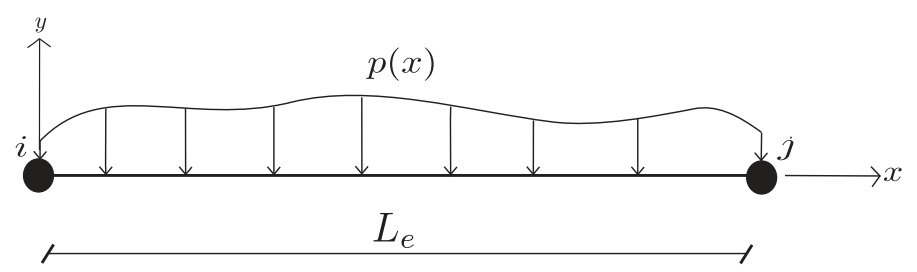

Figure 2. A finite element beam $e$ subjected to a vertical distributed load $p(x)$.

with $N_{\text {shear }}^{T}=\left[\begin{array}{llllll}N_{7} & N_{8} & N_{9} & N_{10} & N_{11} & N_{12}\end{array}\right]$ and the consistent element nodal force vector that becomes:

$$
F_{\text {ext }, \text { element }}=\int_{0}^{L_{e}} N_{\text {shear }}^{T} p(x) \mathrm{d} x=\int_{0}^{L_{e}}\left[\begin{array}{llllll}
N_{7} & N_{8} & N_{9} & N_{10} & N_{11} & N_{12}
\end{array}\right]^{T} p(x) \mathrm{d} x
$$

\section{FLI, FCQM and FCQ formulations}

We present hereafter the shape functions, the stiffness matrices and the consistent nodal force vectors for the FLI, FCQM and FCQ formulations.

\subsection{FLI formulation}

Linear independent shape functions are adopted for the generalised displacement fields (Guedes et al., 1994; Pegon, 1994):

$$
\begin{gathered}
{\left[\begin{array}{l}
U_{x} \\
U_{y} \\
\Theta_{z}
\end{array}\right]=\left[\begin{array}{cccccc}
N_{1} & 0 & 0 & N_{4} & 0 & 0 \\
0 & N_{8} & 0 & 0 & N_{11} & 0 \\
0 & 0 & N_{15} & 0 & 0 & N_{18}
\end{array}\right]\left[\begin{array}{l}
U_{x i} \\
U_{y i} \\
\Theta_{z i} \\
U_{x j} \\
U_{y j} \\
\Theta_{z j}
\end{array}\right],} \\
\text { where }\left\{\begin{array}{l}
N_{1}=N_{8}=N_{15}=1-\frac{x}{L_{e}} \\
N_{4}=N_{11}=N_{18}=\frac{x}{L_{e}}
\end{array}\right.
\end{gathered}
$$

The adopted generalised strain field has the following form:

$$
\left[\begin{array}{c}
U_{x}^{\prime} \\
\beta_{y} \\
\Theta_{z}^{\prime}
\end{array}\right]=\left[\begin{array}{cccccc}
-\frac{1}{L_{e}} & 0 & 0 & \frac{1}{L_{e}} & 0 & 0 \\
0 & -\frac{1}{L_{e}} & -\frac{1}{2} & 0 & \frac{1}{L_{e}} & -\frac{1}{2} \\
0 & 0 & -\frac{1}{L_{e}} & 0 & 0 & \frac{1}{L_{e}}
\end{array}\right]\left[\begin{array}{c}
U_{x i} \\
U_{y i} \\
\Theta_{z i} \\
U_{x j} \\
U_{y j} \\
\Theta_{z j}
\end{array}\right]
$$


where following the proposal of Donea and Lamain (1987), the expression of $\beta_{y}$ is modified by eliminating the linear terms in the shape functions $N_{15}$ and $N_{18}$ ( $\beta_{y}$ component) in order to avoid the shear locking problem. The section and the element stiffness matrices are evaluated according to (11) and (15). For the case of an homogeneous elastic section (a classical Timoshenko elastic beam) the element stiffness becomes:

$$
K_{\text {element }}=\left[\begin{array}{cccccc}
\frac{E S}{L_{e}} & 0 & 0 & -\frac{E S}{L_{e}} & 0 & 0 \\
0 & \frac{k S G}{L_{e}} & \frac{k S G}{2} & 0 & -\frac{k S G}{L_{e}} & \frac{k S G}{2} \\
0 & \frac{k S G}{2} & \frac{E I}{L_{e}}+\frac{k S G L_{e}}{4} & 0 & -\frac{k S G}{2} & -\frac{E I}{L_{e}}+\frac{k S G L_{e}}{4} \\
-\frac{E S}{L_{e}} & 0 & 0 & \frac{E S}{L_{e}} & 0 & 0 \\
0 & -\frac{k S G}{L_{e}} & -\frac{k S G}{2} & 0 & \frac{k S G}{L_{e}} & -\frac{k S G}{2} \\
0 & \frac{k S G}{2} & -\frac{E I}{L_{e}}+\frac{k S G L_{e}}{4} & 0 & -\frac{k S G}{2} & \frac{E I}{L_{e}}+\frac{k S G L_{e}}{4}
\end{array}\right],
$$

where $E$ and $G$ the Young modulus and the Shear modulus, $I$ and $S$ the quadratic moment and the section surface, respectively. The consistent element nodal force for a n-order polynomial $p(x)=q x^{n}$, using (19) and (21), is found as:

$$
F_{\text {ext,element }}=\frac{q L_{e}^{n+1}}{(n+1)(n+2)}\left[\begin{array}{c}
0 \\
1 \\
0 \\
0 \\
n+1 \\
0
\end{array}\right]
$$

\subsection{FCQM formulation}

Cubic and quadratic interdependent polynomials, functions of the material properties, are used for the transverse and rotational displacements and the formulation is free of shear locking (Friedman \& Kosmatka, 1993). The generalised displacement and strain fields are:

$$
\begin{gathered}
{\left[\begin{array}{l}
U_{x} \\
U_{y} \\
\Theta_{z}
\end{array}\right]=\left[\begin{array}{cccccc}
N_{1} & 0 & 0 & N_{4} & 0 & 0 \\
0 & N_{8} & N_{9} & 0 & N_{11} & N_{12} \\
0 & N_{14} & N_{15} & 0 & N_{17} & N_{18}
\end{array}\right]\left[\begin{array}{c}
U_{x i} \\
U_{y i} \\
\Theta_{z i} \\
U_{x j} \\
U_{y j} \\
\Theta_{z j}
\end{array}\right] .} \\
{\left[\begin{array}{l}
U_{x}^{\prime} \\
\beta_{y} \\
\Theta_{z}^{\prime}
\end{array}\right]=\left[\begin{array}{cccccc}
N_{1}^{\prime} & 0 & 0 & N_{4}^{\prime} & 0 & 0 \\
0 & N_{8}^{\prime}-N_{14} & N_{9}^{\prime}-N_{15} & 0 & N_{11}^{\prime}-N_{17} & N_{12}^{\prime}-N_{18} \\
0 & N_{14}^{\prime} & N_{15}^{\prime} & 0 & N_{17}^{\prime} & N_{18}^{\prime}
\end{array}\right]\left[\begin{array}{l}
U_{x i} \\
U_{y i} \\
\Theta_{z i} \\
U_{x j} \\
U_{y j} \\
\Theta_{z j}
\end{array}\right] .}
\end{gathered}
$$


and the shape functions:

$$
\left\{\begin{array}{l}
N_{1}=1-\frac{x}{L_{e}} \\
N_{4}=\frac{x}{L_{e}} \\
N_{8}=\frac{1}{1+\phi}\left[2\left(\frac{x}{L_{e}}\right)^{3}-3\left(\frac{x}{L_{e}}\right)^{2}-\phi\left(\frac{x}{L_{e}}\right)+1+\phi\right] \\
N_{9}=\frac{L_{e}}{1+\phi}\left[\left(\frac{x}{L_{e}}\right)^{3}-\left(2+\frac{\phi}{2}\right)\left(\frac{x}{L_{e}}\right)^{2}+\left(1+\frac{\phi}{2}\right)\left(\frac{x}{L_{e}}\right)\right] \\
N_{11}=-\frac{1}{1+\phi}\left[2\left(\frac{x}{L_{e}}\right)^{3}-3\left(\frac{x}{L_{e}}\right)^{2}-\phi\left(\frac{x}{L_{e}}\right)\right] \\
N_{12}=\frac{L_{e}}{1+\phi}\left[\left(\frac{x}{L_{e}}\right)^{3}-\left(1-\frac{\phi}{2}\right)\left(\frac{x}{L_{e}}\right)^{2}-\frac{\phi}{2}\left(\frac{x}{L_{e}}\right)\right] \\
N_{14}=\frac{6}{(1+\phi) L}\left[\left(\frac{x}{L_{e}}\right)^{2}-\left(\frac{x}{L_{e}}\right)\right] \\
N_{15}=\frac{1}{1+\phi}\left[3\left(\frac{x}{L_{e}}\right)^{2}-(4+\phi)\left(\frac{x}{L_{e}}\right)+1+\phi\right] \\
N_{17}=-\frac{6}{(1+\phi) L}\left[\left(\frac{x}{L_{e}}\right)^{2}-\left(\frac{x}{L_{e}}\right)\right] \\
N_{18}=\frac{1}{1+\phi}\left[3\left(\frac{x}{L_{e}}\right)^{2}-(2-\phi)\left(\frac{x}{L_{e}}\right)\right]
\end{array},\right.
$$

with $\phi$ the ratio of the beam bending to shear stiffness provided by ( $v$ the Poisson's ratio):

$$
\phi=\frac{12}{L_{e}^{2}}\left(\frac{E I}{k G A}\right)=\frac{24}{L_{e}^{2}}\left(\frac{I}{k A}\right)(1+v) .
$$

For the case on an elastic homogeneous material, the element stiffness matrix and the consistent element nodal force vector for a n-order polynomial $p(x)=q x^{n}$ become:

$$
\begin{aligned}
K_{\text {element }}= & {\left[\begin{array}{cccccc}
\frac{E S}{L_{e}} & 0 & 0 & -\frac{E S}{L_{e}} & 0 & 0 \\
0 & \frac{12 E I}{(1+\phi) L_{e}^{3}} & \frac{6 E I}{(1+\phi) L_{e}^{2}} & 0 & -\frac{12 E I}{(1+\phi) L_{e}^{3}} & \frac{6 E I}{(1+\phi) L_{e}^{2}} \\
0 & \frac{6 E I}{(1+\phi) L_{e}^{2}} & \frac{(4+\phi) E I}{(1+\phi) L_{e}} & 0 & -\frac{6 E I}{(1+\phi) L_{e}^{2}} & \frac{(2-\phi) E I}{(1+\phi) L_{e}} \\
-\frac{E S}{L_{e}} & 0 & 0 & \frac{E S}{L_{e}} & 0 & 0 \\
0 & -\frac{12 E I}{(1+\phi) L_{e}^{3}} & -\frac{6 E I}{(1+\phi) L_{e}^{2}} & 0 & \frac{12 E I}{(1+\phi) L_{e}^{3}} & -\frac{6 E I}{(1+\phi) L_{e}^{2}} \\
0 & \frac{6 E I}{(1+\phi) L_{e}^{2}} & \frac{(2-\phi) E I}{(1+\phi) L_{e}} & 0 & -\frac{6 E I}{(1+\phi) L_{e}^{2}} & \frac{(4+\phi) E I}{(1+\phi) L_{e}}
\end{array}\right] } \\
F_{\text {ext,element }} & \frac{q L_{e}^{n+1}}{(1+\phi)(D)}\left[\begin{array}{c}
0 \\
6 n+12+\phi\left(n^{2}+7 n+12\right) \\
L_{e}(n+1)\left[2+\frac{\phi}{2}(n+4)\right] \\
(n+1)[(n+2)(n+6)+\phi(n+3)(n+4)] \\
-L_{e}(n+1)\left[n+2+\frac{\phi}{2}(n+4)\right]
\end{array}\right] .
\end{aligned}
$$




\subsection{FCQ formulation}

Cubic functions are used to interpolate the transverse displacements and quadratic for the rotations. The element is free of shear locking and uses an additional internal node (Caillerie et al., 2015). Caillerie et al. (2015) proved also that the FCQM formulation can be derived from the present formulation and that one FCQ element is able to predict the exact tip displacements for any complex loading (shear/flexion) subjected to an homogeneous elastic beam (see also the numerical examples of Sections 4.2 and 4.3). The latter property is related to the well-known Tong's proof (Tong \& Pian, 1969). Indeed, the interdependent nature and the high order of the selected polynomials (Caillerie et al., 2015) satisfy the differential equations of equilibrium associated with the homogeneous form of the Timoshenko's beam theory (Timoshenko, 1921). The reader is referred to Zienkiewicz and Taylor (2000) for more details.

The nodal displacement field takes the following form:

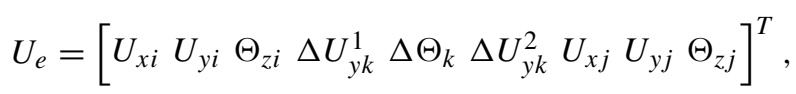

where $\Delta U_{y k}^{1}, \Delta \Theta_{k}$ and $\Delta U_{y k}^{2}$ are the degrees of freedom of the internal node ' $k$ ' (with no specific physical meaning).

The generalised displacement field is:

$$
\begin{aligned}
& {\left[\begin{array}{l}
U_{x} \\
U_{y} \\
\Theta_{z}
\end{array}\right]=\left[\begin{array}{ccccccccc}
N_{1} & 0 & 0 & 0 & 0 & 0 & N_{7} & 0 & 0 \\
0 & N_{11} & 0 & N_{13} & 0 & N_{15} & 0 & N_{17} & 0 \\
0 & 0 & N_{21} & 0 & N_{23} & 0 & 0 & 0 & N_{27}
\end{array}\right]\left[\begin{array}{c}
U_{x i} \\
U_{y i} \\
\Theta_{z i} \\
\Delta U_{y k}^{1} \\
\Delta \Theta_{k} \\
\Delta U_{y k}^{2} \\
U_{x j} \\
U_{y j} \\
\Theta_{z j}
\end{array}\right]} \\
& \text { where }\left\{\begin{array}{l}
N_{1}=1-\frac{x}{L_{e}} \\
N_{7}=\frac{x}{L_{e}} \\
N_{11}=\left(1-\frac{x}{L_{e}}\right)^{2}\left(1+2 \frac{x}{L_{e}}\right) \\
N_{13}=2\left(1-\frac{x}{L_{e}}\right)^{2}\left(\frac{x}{L_{e}}\right) \\
N_{17}=-2\left(\frac{x}{L_{e}}\right)^{2}\left(1-\frac{x}{L_{e}}\right) \\
N_{21}=\left(1-\frac{x}{L_{e}}\right)\left(3-2 \frac{x}{L_{e}}\right) \\
N_{23}=1-\left(1-2 \frac{x}{L_{e}}\right)^{2} \\
N_{27}=-\left(\frac{x}{L_{e}}\right)\left(2-3 \frac{x}{L_{e}}\right)
\end{array}\right.
\end{aligned}
$$


This gives for the generalised strain field:

$$
\left[\begin{array}{c}
U_{x}^{\prime} \\
\beta_{y} \\
\Theta_{z}^{\prime}
\end{array}\right]=\left[\begin{array}{ccccccccc}
N_{1}^{\prime} & 0 & 0 & 0 & 0 & 0 & N_{7}^{\prime} & 0 & 0 \\
0 & N_{11}^{\prime} & -N_{21} & N_{13}^{\prime} & -N_{23} & N_{15}^{\prime} & 0 & N_{17}^{\prime} & -N_{27} \\
0 & 0 & N_{21}^{\prime} & 0 & N_{23}^{\prime} & 0 & 0 & 0 & N_{27}^{\prime}
\end{array}\right]\left[\begin{array}{c}
U_{x i} \\
U_{y i} \\
\Theta_{z i} \\
\Delta U_{y k}^{1} \\
\Delta \Theta_{k} \\
\Delta U_{y k}^{2} \\
U_{x j} \\
U_{y j} \\
\Theta_{z j}
\end{array}\right] .
$$

For the case on an elastic homogeneous material, the element stiffness matrix and the consistent element nodal force vector for a n-order polynomial $p(x)=q x^{n}$ become:

$$
\begin{aligned}
& \begin{array}{l}
K_{\text {element }} \\
=\left[\begin{array}{ccccccccc}
\frac{E S}{L_{e}} & 0 & 0 & 0 & 0 & 0 & -\frac{E S}{L_{e}} & 0 & 0 \\
0 & \frac{6 k G S}{5 L_{e}} & -\frac{k G S}{10} & \frac{k G S}{5 L_{e}} & \frac{4 k G S}{5} & \frac{k G S}{5 L_{e}} & 0 & -\frac{6 k G S}{5 L_{e}} & -\frac{k G S}{10} \\
0 & -\frac{k G S}{10} & \frac{2 k G L_{e} S}{15}+\frac{4 E I}{L_{e}} & -\frac{4 k G S}{15} & -\frac{k G L_{e} S}{15}-\frac{4 E I}{L_{e}} & \frac{k G S}{15} & 0 & \frac{k G S}{10} & \frac{2 E I}{L_{e}}-\frac{k G L_{e} S}{30} \\
0 & \frac{k G S}{5 L_{e}} & -\frac{4 k G S}{15} & \frac{8 k G S}{15 L_{e}} & \frac{2 k G S}{15} & -\frac{2 k G S}{15 L_{e}} & 0 & -\frac{k G S}{5 L_{e}} & \frac{k G S}{15} \\
0 & \frac{4 k G S}{5} & -\frac{k G L_{e} S}{15}-\frac{4 E I}{L_{e}} & \frac{2 k G S}{15} & \frac{8 k G L_{e} S}{15}+\frac{16 E I}{3 L_{e}} & \frac{2 k G S}{15} & 0 & -\frac{4 k G S}{5} & -\frac{k G L_{e} S}{15}-\frac{4 E I}{L_{e}} \\
0 & \frac{k G S}{5 L_{e}} & \frac{k G S}{15} & -\frac{2 k G S}{15 L_{e}} & \frac{2 k G S}{15} & \frac{8 k G S}{15 L_{e}} & 0 & -\frac{k G S}{5 L_{e}} & -\frac{4 k G S}{15} \\
-\frac{E S}{L_{e}} & 0 & 0 & 0 & 0 & 0 & \frac{E S}{L_{e}} & 0 & 0 \\
0 & -\frac{6 k G S}{5 L_{e}} & \frac{k G S}{10} & -\frac{k G S}{5 L_{e}} & -\frac{4 k G S}{5} & -\frac{k G S}{5 L_{e}} & 0 & \frac{6 k G S}{5 L_{e}} & \frac{k G S}{10} \\
0 & -\frac{k G S}{10} & \frac{2 E I}{L_{e}}-\frac{k G L_{e} S}{30} & \frac{k G S}{15} & -\frac{k G L_{e} S}{15}-\frac{4 E I}{L_{e}} & -\frac{4 k G S}{15} & 0 & \frac{k G S}{10} & \frac{2 k G L_{e} S}{15}+\frac{4 E I}{L_{e}}
\end{array}\right] .
\end{array} \\
& F_{\text {ext, element }}=\frac{q L_{e}^{n+1}}{D}\left[\begin{array}{c}
0 \\
6(n+2) \\
0 \\
4(n+1) \\
0 \\
-2(n+1)(n+2) \\
0 \\
(n+1)(n+2)(n+6) \\
0
\end{array}\right]
\end{aligned}
$$

where

$$
D=(n+1)(n+2)(n+3)(n+4) \text {. }
$$

The introduction of internal degrees of freedom leads to $9 \times 9$ matrices (rather than $6 \times 6$ ) and to $9 \times 1$ vectors. To use this element to a general purpose finite element code, one has to calculate the internal degrees of freedom using two approaches: either the internal degrees of freedom are treated as external degrees of freedom and are sent to the global solver of the finite element code either they are calculated locally (inside the element subroutine) using the static condensation method (see Caillerie et al., 2015) for more details and the analytical expressions of the condensed matrices and vectors). 


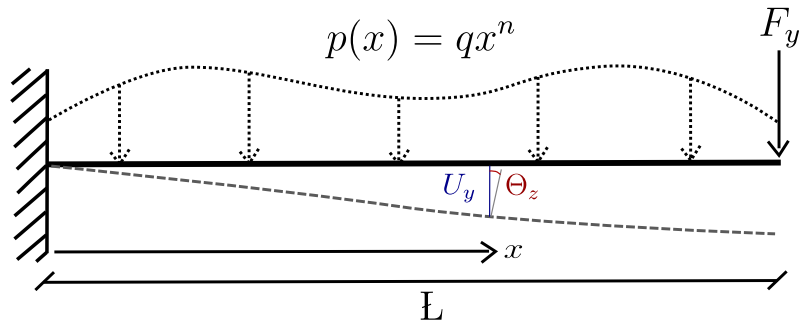

Figure 3. Cantilever beam under distributed load and vertical punctual force.

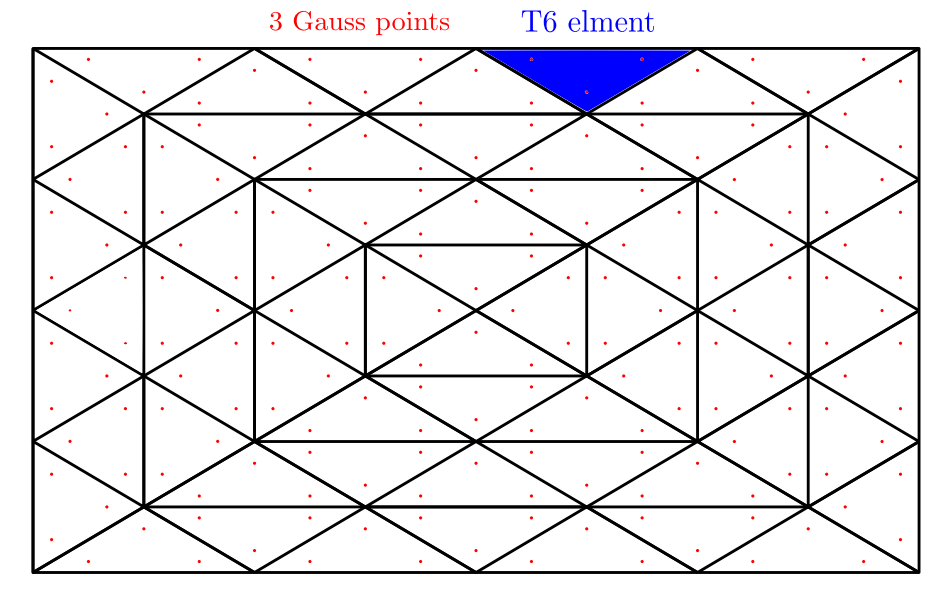

Figure 4. Gauss's points distribution in a section.

\section{Comparison of the FLI, FCQM and FCQ formulations}

\subsection{Preliminaries}

In order to study the accuracy of the different formulations, the analytical solution for the case of an homogeneous Timoshenko cantilever beam structure of length $€$ subjected to vertical punctual force $F_{y}$ at the free end $(x=\mathrm{E})$ and to a polynomial $p(x)=q x^{n}$ distributed vertical force takes the following form (for more details see Caillerie et al., 2015) Figure 3:

$$
\begin{aligned}
\Theta_{z}=\frac{F_{y}}{2 E I}\left[x^{2}-2 x €\right]+\frac{1}{E I}\left[\frac{q \bigsqcup^{n+2}}{n+2} x\right. & \left.-\frac{q \mathrm{Ł}^{n+1}}{2(n+1)} x^{2}+\frac{q}{(n+1)(n+2)(n+3)}\right] \\
U_{y}=\frac{F_{y}}{2 E I}\left[\frac{x^{3}}{3}-x^{2} €\right]-\frac{F_{y} x}{k G S} & +\frac{q}{k G S(n+1)}\left[\mathrm{七}^{n+1} x-\frac{x^{n+2}}{n+2}\right] \\
& +\frac{q}{E I}\left[\frac{\bigsqcup^{n+2}}{2(n+2)} x^{2}-\frac{\bigsqcup^{n+1}}{6(n+1)} x^{3}\right. \\
& \left.+\frac{x^{n+4}}{(n+1)(n+2)(n+3)(n+4)}\right]
\end{aligned}
$$




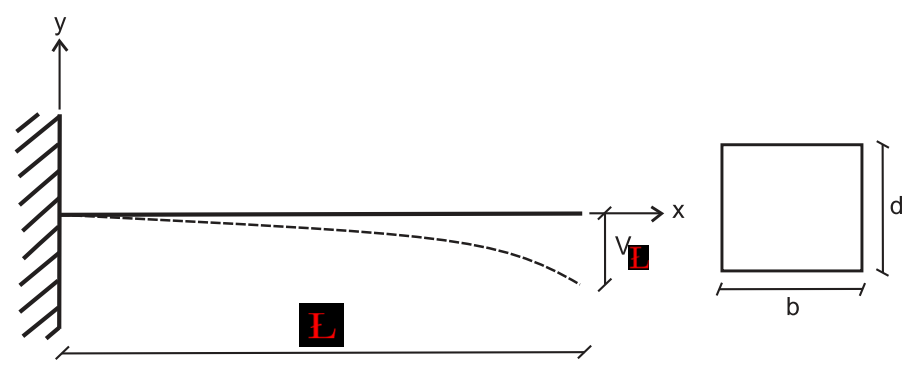

Figure 5. Cantilever beam.

For the numerical examples presented hereafter, numerical integrations are performed in each section and along the axis of the multi-fiber beams. Each section is discretised using 64 triangular finite elements (T6), where each $T 6$ has 6 nodes and 3 Gauss integration points. In this way, the section stiffness matrices and the section force vectors are exactly integrated for the case of an elastic material behaviour (Bitar, 2013) (e.g. the $\int_{S} E_{f} y^{2} \mathrm{~d} S$ component in the section stiffness matrix (11) requires at least 3 integration points as the interpolation functions for $T 6$ are of order 2). The numerical integration of Equation (15) along the beam $x$ axis is performed according to the Gauss integration scheme using one (1) Gauss's point for the FLI, two (2) for the FCQM (the components of the matrix $B$ Equation (26) are linear) and three (3) for the FCQ formulation (the derivatives of the transverse displacement interpolation functions being quadratic (33), the exact numerical integration of $\int_{0}^{L_{e}} \underbrace{B^{T} K_{S} B}_{O(4)} \mathrm{d} x(15)$ requires at least three Gauss integration points).

Different numerical examples chosen to illustrate the performance of the FLI, FCQM and FCQ beam formulations are Figure 4:

4.2 A cantilever elastic Timoshenko beam subjected to a transverse tip displacement.

4.3 A cantilever elastic Timoshenko beam subjected to a polynomial $p(x)=q x^{n}$ vertical force.

4.4 A cantilever elastic perfectly plastic Timoshenko beam subjected to a transverse tip displacement. 4.5 A simple elastic perfectly plastic Timoshenko beam subjected to a rotation and an axial force.

Remark: In the FCQM formulation, the shape functions depend on the material properties (27),(28). The performance of the multi-fiber Timoshenko beam for non linear calculations can therefore be undpredictable (Caillerie et al., 2015). This is the reason why in the following, the FCQM formulation is not tested with the elasto-plastic applications 4.4 and 4.5.

\subsection{A cantilever elastic Timoshenko beam subjected to a transverse tip displacement}

The geometrical characteristics of the beam structure and the material parameters are given in Figure 5 and Table 1.

A displacement $v_{\mathrm{E}}$ is applied at $x=€$. The resulting analytical shear force at $x=0$ is given as (see also Equation (38) considering $q=0$ and $x=\mathrm{E}$ ) (Association française de normalisation):

$$
F_{y}^{\mathrm{ana}}=\frac{v_{€}}{\frac{Ł^{3}}{3 E I}+\frac{£}{k G S}}
$$


Table 1. Cantilever beam - geometrical characteristics and material properties.

\begin{tabular}{lcccc}
\hline Geometry & & \multicolumn{3}{c}{ Material properties } \\
\hline$Ł$ & $1.53 \mathrm{~m}$ & Young modulus & $E$ & $210 \mathrm{GPa}$ \\
$b$ & $0.25 \mathrm{~m}$ & Poisson's ratio & $v$ & 0.3 \\
$d$ & $0.25 \mathrm{~m}$ & Shear correction factor & $k$ & $\frac{5}{6}$ \\
\hline
\end{tabular}

Table 2. A cantilever elastic Timoshenko beam subjected to a transverse tip displacement. Results of the three formulations considering one (1) multi-fiber Timoshenko beam element.

\begin{tabular}{lccccc}
\hline & $n$ & $v_{\mathrm{E}}(\mathrm{m})$ & $F_{y}(\mathrm{KN})$ & $M_{z}(\mathrm{KNm})$ & $R_{E}\left(F_{y}\right)(\%)$ \\
\hline Analytical & 1 & 0.1 & 5609.1 & 8581.9 & - \\
FLI & 1 & 0.1 & 7428.3 & 11365.3 & 32 \\
FCQM & 1 & 0.1 & 5609.1 & 8581.9 & 0 \\
FCQ & 1 & 0.1 & 5609.1 & 8581.9 & 0 \\
\hline
\end{tabular}

Table 3. A cantilever elastic Timoshenko beam subjected to a transverse tip displacement. Results of the FLI formulation considering $n$ multi-fiber Timoshenko beam elements.

\begin{tabular}{lccccccc}
\hline$n$ & $F_{y}(\mathrm{KN})$ & $M_{z}(\mathrm{KNm})$ & $R_{E}\left(F_{y}\right)(\%)$ & $n$ & $F_{y}(\mathrm{KN})$ & $M_{z}(\mathrm{KNm})$ & $R_{E}\left(F_{y}\right)(\%)$ \\
\hline 4 & 5696.3 & 8715.3 & 1.5 & 20 & 5612.2 & 8587.2 & 0.053 \\
8 & 5630.6 & 8614.9 & 0.37 & 31 & 5610.5 & 8584.1 & 0.025 \\
16 & 5614.5 & 8590.1 & 0.087 & 51 & 5609.6 & 8582.73 & 0.009 \\
\hline
\end{tabular}

and the corresponding moment:

$$
M_{z}^{\text {ana }}=€ \times F_{y}^{\text {ana }}
$$

Comparison of the performances of the three formulations is provided in Tables 2 and 3 where $n$ is the number of the multi-fiber Timoshenko beam elements used for the spatial discretisation and $R_{E}\left(F_{y}\right)$ the relative error on shear forces defined as:

$$
R_{E}\left(F_{y}\right)=\left|\frac{F_{y}^{\text {ana }}-F_{y}^{\text {num }}}{F_{y}^{\text {ana }}}\right|
$$

with $F_{y}^{\text {num }}$ the result of the numerical calculations.

One (1) FCQM or FCQ element provides the exact solution in terms of forces and moments, whereas the FLI formulation presents a relative error $R_{E}\left(F_{y}\right)$ of $32 \%$, see Table 2. This is due to the fact that its shape functions corresponding to the transverse displacements and rotations are linear, whereas the analytical solutions of $\Theta_{z}$ and $U_{y}$ are a second- and a third-order polynomial, respectively (see Equations (37), (38) considering $q=0$ ). By increasing the number of elements, the accuracy of the FLI formulation however quickly improves (see Table 3). 
Table 4. A cantilever elastic Timoshenko beam subjected to a polynomial $p(x)=-20 x^{2}$ vertical force. Results of the three formulations considering one (1) multi-fiber Timoshenko beam element.

\begin{tabular}{lccccc}
\hline & $F_{y}(\mathrm{KN})$ & $M_{z}(\mathrm{KNm})$ & $v\left(10^{-3}\right)$ & $\theta\left(10^{-3}\right)$ & $R_{E}(\theta)(\%)$ \\
\hline Analytical & 23.9 & 27.4 & -0.2776 & -0.2453 & - \\
FLI & 23.9 & 27.4 & -0.2411 & -0.3066 & 25 \\
FCQM & 23.9 & 27.4 & -0.2776 & -0.2453 & 0 \\
FCQ & 23.9 & 27.4 & -0.2776 & -0.2453 & 0 \\
\hline
\end{tabular}

Table 5. A cantilever elastic Timoshenko beam subjected to a polynomial $p(x)=-20 x^{2}$ vertical force. Results of the FLI formulation considering $n$ multi-fiber Timoshenko beam elements.

\begin{tabular}{lrrrc}
\hline$n$ & $v\left(10^{-3}\right)$ & $R_{E}(v)(\%)$ & $\theta\left(10^{-3}\right)$ & $R_{E}(\theta)(\%)$ \\
\hline 1 & -0.2411 & 13.15 & -0.3066 & 25 \\
4 & -0.2744 & 1.15 & -0.2495 & 1.7 \\
8 & -0.2768 & 0.29 & -0.2464 & 0.45 \\
16 & -0.2774 & 0.07 & -0.2456 & 0.12 \\
\hline
\end{tabular}

\subsection{A cantilever elastic Timoshenko beam subjected to a polynomial $p(x)=q x^{n}$ vertical force}

A 2-order distributed load $p(x)=-20 x^{2}$ is applied on the previous cantilever beam. The vertical displacements and rotations at the free end for the different finite element formulations and for different discretisations are given in Tables 4 and 5. The analytical values are calculated from (37) and (38) considering $F_{y}=0, q=-20$ and $n=2$, see also (Caillerie et al., 2015).

Again, one (1) FCQM or FCQ multi-fiber Timoshenko beam provides the exact results. Because of the adopted linear shape functions, one (1) FLI element gives a relative error on rotations $R_{E}(\theta)$ (defined in a similar way as (41)) of $25 \%$. Since the calculation is forced controlled, numerical results on shear forces and moments are exact for all formulations. The accuracy of the FLI formulation improves rapidly with the increase of the number of elements; the relative error drops from $25 \%$ (one element) to $1.7 \%$ (four elements), Table 5.

\subsection{A cantilever elastic perfectly plastic Timoshenko beam subjected to a transverse tip displacement}

We consider hereafter an elastic perfectly plastic material (Simo \& Hughes, 1998) assuming that only the normal component of the axial stress $\sigma_{x}$ can enter to plasticity. No interaction between the shear stresses and the normal stresses at the material constitutive law level is considered. The stress elastic limit $f_{y}$ is taken equal to $450 \mathrm{MPa}$, while the other parameters are provided in Table 1. The plastic moment is (Eurocode 2 De Normalisation, 2004):

$$
M_{p l}=W_{p l} f_{y}=\frac{b d^{2}}{4} f_{y}
$$


Table 6. A cantilever elastic perfectly plastic Timoshenko beam subjected to a transverse tip displacement. Results of two formulations considering one multi-fiber Timoshenko beam.

\begin{tabular}{lcrrrr}
\hline & $n$ & $v_{\mathrm{E}}(m)$ & $F_{y}(\mathrm{KN})$ & $M_{z}(\mathrm{KNm})$ & $R_{E}\left(F_{y}\right)(\%)$ \\
\hline Analytical & 1 & 0.1 & 1148.9 & 1757.8 & - \\
FLI & 1 & 0.1 & 2263 & 3462 & 97 \\
FCQ & 1 & 0.1 & 1581 & 2417 & 37.6 \\
\hline
\end{tabular}

Table 7. A cantilever elastic perfectly plastic Timoshenko beam subjected to a transverse tip displacement. Results of 2 formulations considering $n$ multi-fiber Timoshenko beam elements.

\begin{tabular}{lcccccc}
\hline \multicolumn{3}{c}{ FLI } & \multicolumn{3}{c}{ FCQ } \\
\hline$n$ & $F_{y}(\mathrm{KN})$ & $M_{z}(\mathrm{KNm})$ & $R_{E}\left(F_{y}\right)(\%)$ & $F_{y}(\mathrm{KN})$ & $M_{z}(\mathrm{KNm})$ & $R_{E}\left(F_{y}\right)(\%)$ \\
4 & 1312 & 2006 & 14 & 1236 & 1889 & 7.7 \\
8 & 1225 & 1872 & 7 & 1191 & 1819 & 4.1 \\
16 & 1186 & 1811 & 3.2 & 1169 & 1785 & 1.7 \\
\hline
\end{tabular}

and the plastic shear force:

$$
F_{\mathrm{yp}}=\frac{M_{p l}}{€}
$$

These two values are obtained considering that all the fibers in the section are plastified. This is an asymptotic section behaviour state that cannot be reached with the adopted kinematic assumption of plane sections, since the axial strain at the neutral axis equals zero and thus the corresponding fibers cannot plastified. (One should notice that the shear correction factor $k=5 / 6$ derived from elasticity is adopted in this example, since the shear behaviour is considered elastic).

The cantilever beam structure is subjected to an imposed displacement $v_{\mathrm{E}}$ at its free end $(x=€)$. Comparison of the performances of the two formulations for different discretisations are shown in Tables 6 and 7. As before, one (1) FLI element does not provide good results. However, increasing the number of elements greatly improves its performance. Results are better for the FCQ formulation that provides the smallest error among the two formulations.

Figure 6 presents the moment diagrams along the beam for the two formulations (FLI and FCQ) and for different number of elements. The moment nodal values are plotted and linked with straight lines. By increasing the number of multi-fiber beam elements, the moment diagrams of the two formulations coincide. Conclusions are similar in Figure 7 showing the evolution of the shear force $F_{y}$ with respect to the vertical tip displacement $v_{Ł}$. Notice that the graphs (6), (7), but also (8), (9) and (10) illustrate the extrapolated nodal values computed from the values at the integration points.

In order to illustrate the mesh dependency problems that can occur when a constitutive law without an internal length parameter is adopted (Armero \& Ehrlich, 2004), Figures 8 and 9 present the axial strain $\varepsilon_{x}$ (3) in an extreme fiber of a section and the section rotation $\Theta_{z}$ (13) along the length of the beam for the two formulations and two discretisations. In all cases a plastic hinge, dependent on the size of the elements, is found concentrated in the first multi-fiber beam element. Different approaches have been proposed in the literature to correctly simulate strain localisation problems: introducing rate dependency (Needleman, 1988), non-local theories (Bažant et al., 1987), higher order media (Chambon et al., 2001) 


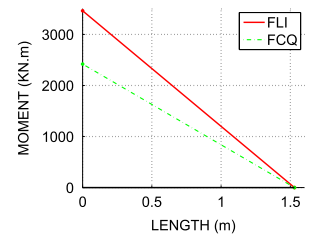

(a) $n=1$

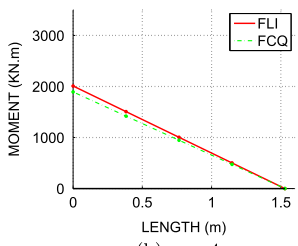

(b) $n=4$

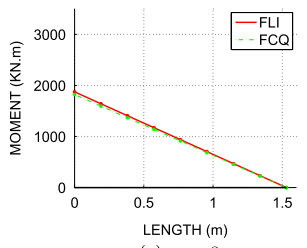

(c) $n=8$

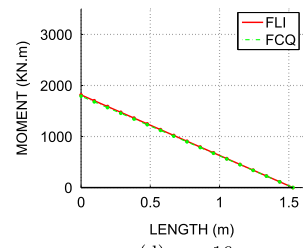

(d) $n=16$

Figure 6. A cantilever elastic perfectly plastic Timoshenko beam subjected to a transverse tip displacement - moment diagrams along the beams for 2 formulations considering $n$ multi-fiber Timoshenko beam elements.

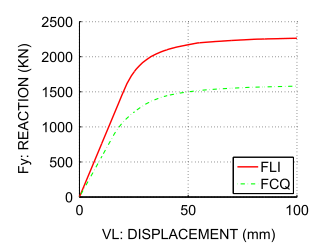

(a) $n=1$

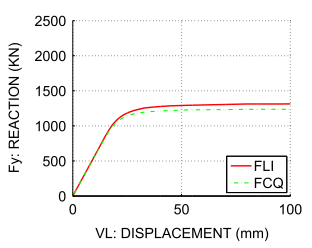

(b) $n=4$

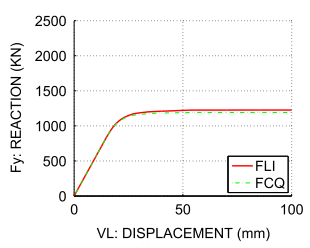

(c) $n=8$

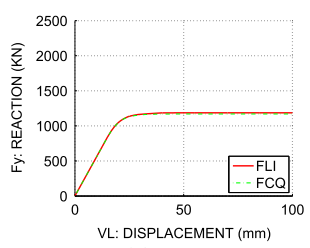

(d) $n=16$

Figure 7. A cantilever elastic perfectly plastic Timoshenko beam subjected to a transverse tip displacement - shear forces vs. vertical displacements for 2 formulations considering $n$ multi-fiber Timoshenko beam elements.

and the so-called enhanced approaches (Armero \& Ehrlich, 2004 and Simo et al., 1993) among others. In Armero and Ehrlich (2004) and in order to regularise the solution, the authors proposed to incorporate the localised dissipative mechanisms in the form of strong discontinuities in the generalised displacements. Localisation issues were also treated within the context of multi-fiber beams, the readers are referred to Coleman and Spacone (2001) for force-based, and to Jukić et al. (2014) and Pham et al. (2012) for displacement-based multi-fiber elements. Nevertheless, strain localiSation issues are out of the scope of the present article.

One should notice however that mesh dependency problems do not appear if an elastoplastic constitutive law with a positive isotropic hardening $K_{H}$ is adopted. The previous example is revisited using $K_{H}=20 \mathrm{MPa}$ and results are shown in Figure 10. One can see that the solution is not spuriously localised at the left end.

\subsection{A simple elastic perfectly plastic Timoshenko beam subjected to a rotation and an axial force}

The purpose of this last example is to study the ability of the proposed multi-fiber beam element formulations to reproduce the interaction between normal forces and bending moments (see Casaux, 2003 and Casaux-Ginestet \& Ibrahimbegovic, 2011). We consider hereafter the simple beam of Figure 11 having an homogeneous cross-section and an elastic perfectly plastic material. The geometric characteristics of the beam and the material properties are given in Table 8. At first, an horizontal increasing force is applied at its right end till a maximal value $F_{\max }$. Then, and while the axial force remains constant, an increasing rotation $\theta$ is applied at its left end.

As illustrated in Figure 11, the beam structure is discretised with two elements, such that $L_{\text {element1 }}=0.8 \mathrm{~m}$ and $L_{\text {element2 }}=1.2 \mathrm{~m} .3$ Gauss points are used for the numerical 


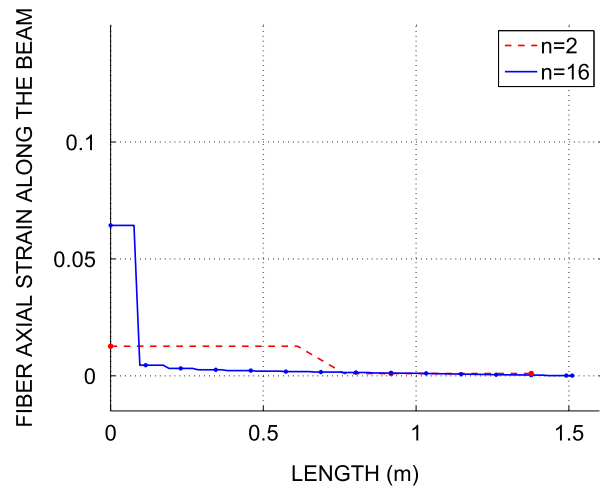

(a) FLI

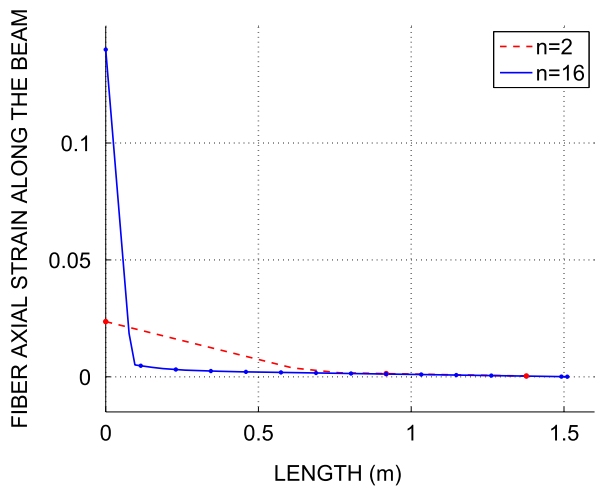

(b) FCQ

Figure 8. A cantilever elastic perfectly plastic Timoshenko beam subjected to a transverse tip displacement - axial strain in an extreme fiber vs. beam length.

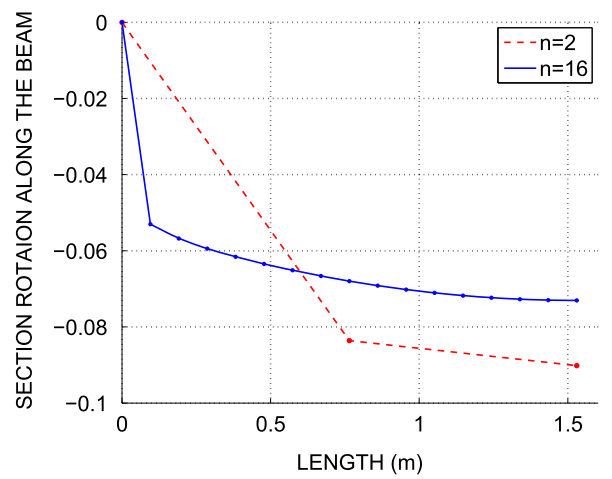

(a) FLI

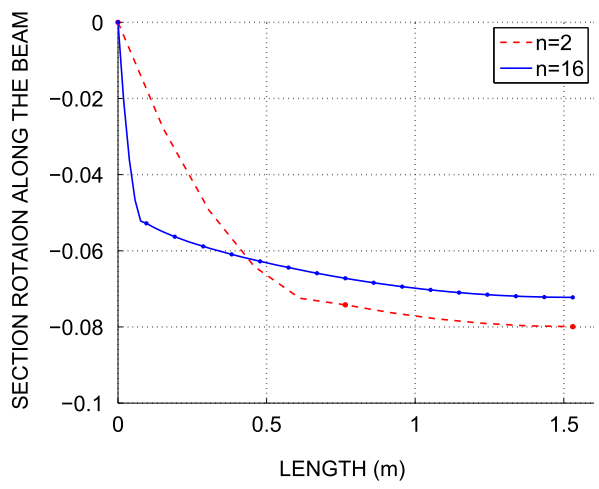

(b) FCQ

Figure 9. A cantilever elastic perfectly plastic Timoshenko beam subjected to a transverse tip displacement - section rotation vs. beam length.

Table 8. Simple beam - geometrical and material characteristics.

\begin{tabular}{|c|c|c|c|c|c|}
\hline Length & $Ł$ & $2 \mathrm{~m}$ & Section & $S$ & $0.2 \mathrm{~m} \times 0.2 \mathrm{~m}$ \\
\hline Young modulus & $E$ & $200000 \mathrm{MPa}$ & Hardening modulus & $K$ & $1 \%$ \\
\hline Stress elastic limit & $f_{y}$ & $500 \mathrm{MPa}$ & Shear correction factor & $k$ & $\frac{5}{6}$ \\
\hline
\end{tabular}

integration along the length of each finite element beam (in order to compare the section response at three different positions within the element). Each section is discretised with 16 fibers. The maximum axial load is taken equal to $F_{\max }=19 \mathrm{MN}$ Figure $12(\mathrm{~b})$ while the history of the imposed rotation $\theta$ is shown in Figure 12(a). Figure 13 presents the evolution of the normal force at the three sections within the first element. The three sections are located at the positions of the three Gauss points used for the numerical integration. The performance of the finite element formulations FLI and FCQ is studied hereafter. 


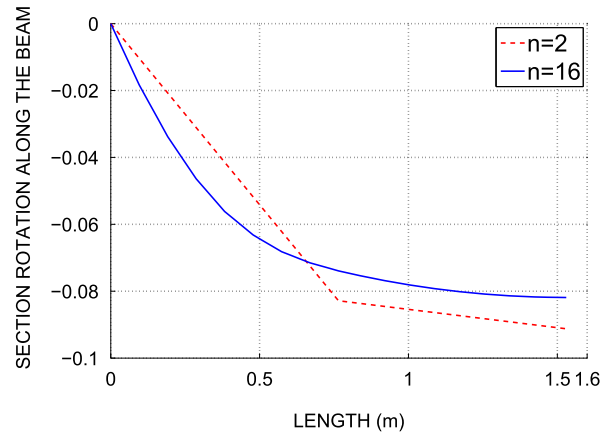

(a) FLI

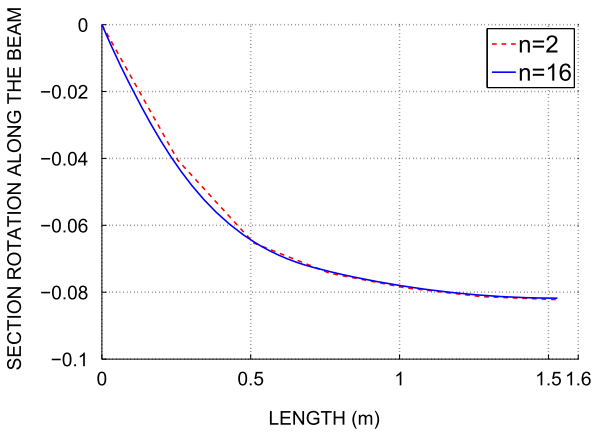

(b) FCQ

Figure 10. A cantilever elastic plastic (with positive hardening) Timoshenko beam subjected to a transverse tip displacement - section rotation vs. beam length.

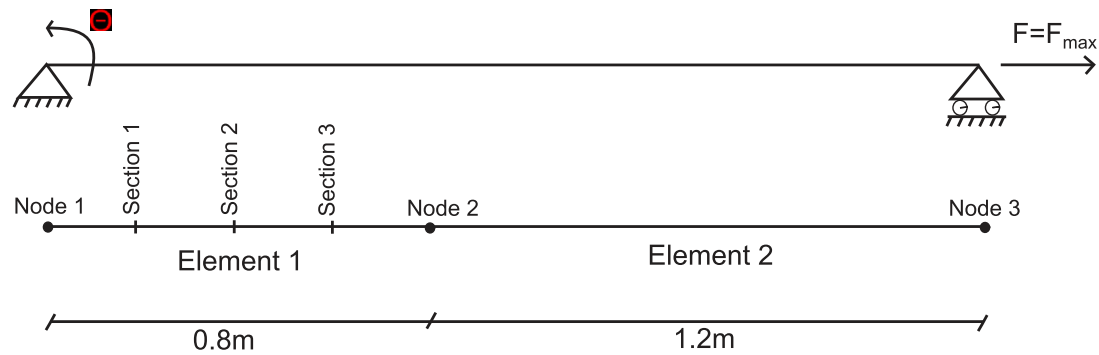

Figure 11. Simple beam.

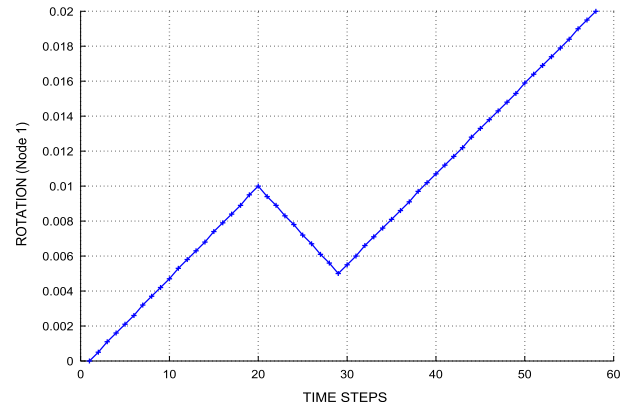

(a) Imposed rotation history

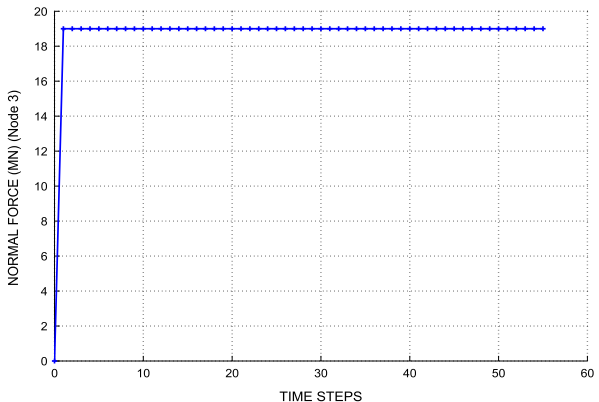

(b) Normal force history

Figure 12. A simple elastic perfectly plastic Timoshenko beam subjected to a rotation and an axial force.

Remark: As already mentioned, only one Gauss point is necessary for the FLI numerical integration. Three Gauss points are however used in this particular example in order to compare with the results at the same sections of the FCQ element.

According to the equilibrium equations, since $\frac{\mathrm{d} F_{x}}{\mathrm{~d} x}=0$ the axial force should remain constant. The numerical expression of the normal force is $F_{x}(x)=\int_{S} E_{f} \mathrm{~d} S U_{x}^{\prime}(x)-$ $\int_{S} E_{f} y \mathrm{~d} S \Theta_{z}^{\prime}(x)(10)$. Linear shape functions are used to interpolate the axial displacements 


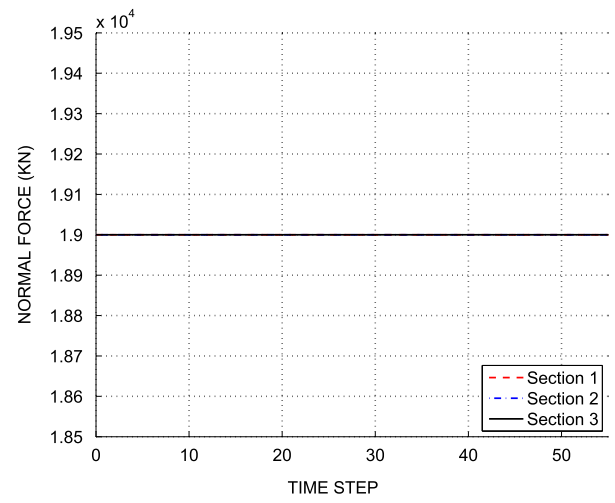

(a) FLI

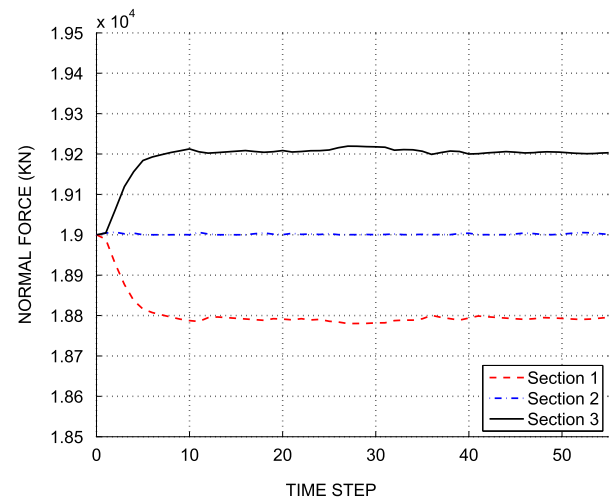

(b) FCQ

Figure 13. A simple elastic perfectly plastic Timoshenko beam subjected to a rotation and an axial force - normal forces at the three sections within the first element for the finite element formulations FLI and FCQ.

$U_{x}(x)(21)$ and (33) leading to a constant value for $U_{x}^{\prime}(x)=\frac{U_{x j}-U_{x i}}{L_{e}}$ along the element and this for the two formulations. The FLI formulation adopts linear shape functions to interpolate $\Theta_{z}(x)$ and therefore $\Theta_{z}^{\prime}(x)=\frac{\Theta_{z j}-\Theta_{z i}}{L_{e}}$ remains also constant. A constant value is thus found for $F_{x}(x)=\int_{S} E_{f} \mathrm{~d} S\left[\frac{U_{x j}-U_{x i}}{L_{e}}\right]-\int_{S} E_{f} y \mathrm{~d} S\left[\frac{\Theta_{z j}-\Theta_{z i}}{L_{e}}\right]$ along the FLI element as shown in Figure 13.

Results are however different for the FCQ formulation. The shape functions used to interpolate $\Theta_{z}(x)$ are quadratic. The expressions of $\Theta_{z}^{\prime}(x)$ can be derived from the corresponding Equation (34) as follows:

$$
\begin{aligned}
\Theta_{z}^{\prime}(x) & =N_{21}^{\prime} \Theta_{z i}+N_{23}^{\prime} \Delta \Theta_{i}+N_{27}^{\prime} \Theta_{z j} \\
& =\frac{2}{L_{e}}\left(-2+\frac{3 x}{L_{e}}\right) \Theta_{z i}+\frac{4}{L_{e}}\left(1-\frac{2 x}{L_{e}}\right) \Delta \Theta_{i}+\frac{2}{L_{e}}\left(-1+\frac{2 x}{L_{e}}\right) \Theta_{z j}
\end{aligned}
$$

Equation (44) shows that $\Theta_{z}^{\prime}(x)$ is linear along the element. This is the reason why the evolution of $F_{x}(x)$ in Figure 13 is different, depending on the element section. For example, in Section 2 which is situated at $x=\frac{L_{e}}{2}$ we have $\Theta_{z}^{\prime}\left(\frac{L_{e}}{2}\right)=\frac{\Theta_{z j}-\Theta_{z i}}{L_{e}}$, and therefore the same result with the FLI formulation is obtained. As shown in Figure 14, increasing the number of the FCQ elements improves the results.

Table 9 presents a brief comparison of the three beam formulations: “*” states for poor results, " $* *$ " for results close to the analytical solution, “***" for results that coincide with the analytical solution.

A more satisfactory solution is proposed in the next section based on the kinematic enhancement of the axial displacement field.

\subsubsection{Kinematic enhancement of the axial displacement field}

Following a similar idea as in the work of Casaux (2003) for multi-fiber Euler-Bernoulli beams, a specific novel kinematic enhancement is proposed for the axial displacements in order to improve the ability of the FCQ Timoshenko beam to deal with non linear axial-bending interactions. Cubic shape functions can be used for the interpolation of the 


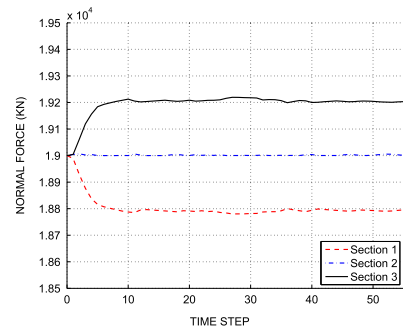

(a) $n=2$

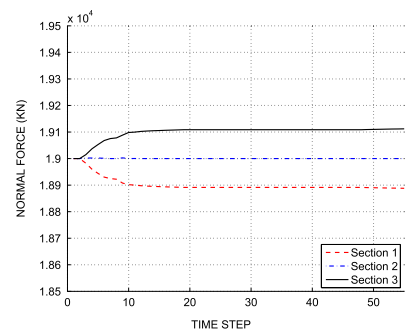

(b) $n=5$

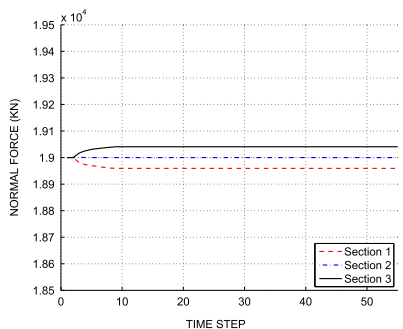

(c) $n=10$

Figure 14. A simple elastic perfectly plastic Timoshenko beam subjected to a rotation and an axial force - Normal force at the 3 sections within the first element for the FCQ formulation using different discretisations.

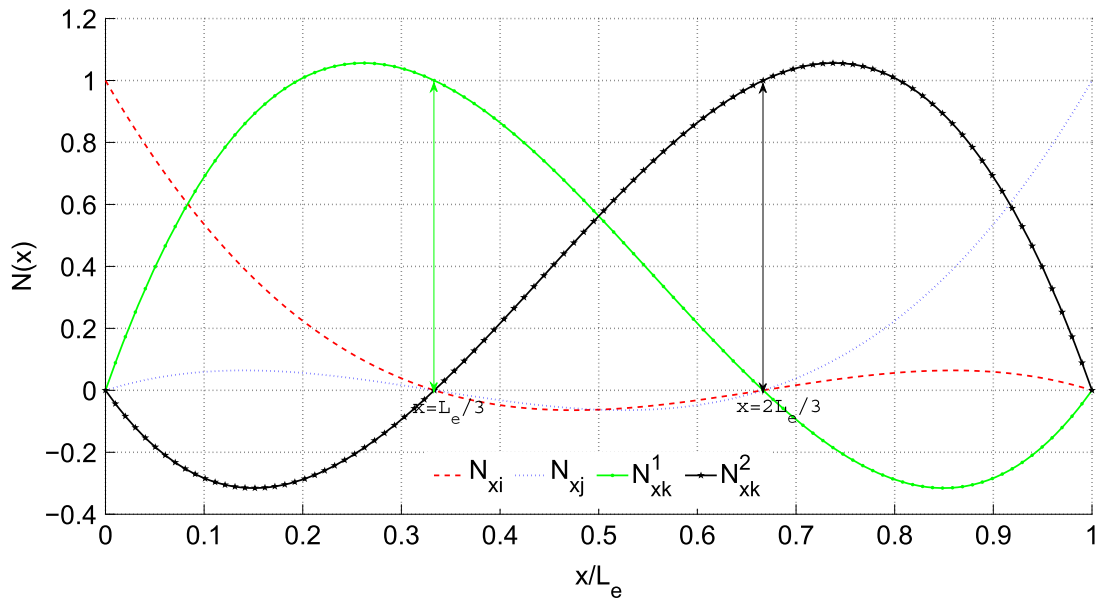

Figure 15. New axial shape functions illustration.

Table 9. Comparison summary of the three finite element beam formulations.

\begin{tabular}{|c|c|c|c|c|c|c|c|}
\hline & \multirow[b]{2}{*}{ Summary } & \multicolumn{2}{|c|}{ FLI } & \multicolumn{2}{|c|}{ FCQM } & \multicolumn{2}{|c|}{ FCQ } \\
\hline & & $n=1$ & high $n$ & $n=1$ & high $n$ & $n=1$ & high $n$ \\
\hline \multirow[t]{2}{*}{ Elastic } & monotonic loading & $* *$ & $* *$ & $* * *$ & $* * *$ & $* * *$ & $* * *$ \\
\hline & polynomial loading & $*$ & $* *$ & $* * *$ & $* * *$ & $* * *$ & $* * *$ \\
\hline \multirow[t]{2}{*}{ Plastic } & monotonic loading & * & $* *$ & & & $* *$ & $* *$ \\
\hline & interaction $\left(F_{x} \& M\right)$ & $*$ & $* *$ & & & $* *$ & $* *$ \\
\hline
\end{tabular}

axial displacements, which mathematically requires the addition of two additional internal degrees of freedom. Indeed, four linearly independent polynomials are needed to form a basis for degree three polynomials. The polynomial coefficients are chosen such as to respect the boundary displacements of the element $\left(U(x=0)=U_{x i}\right.$ and $\left.U\left(x=L_{e}\right)=U_{x j}\right)$ and also to respect two additional requirements $\left(U\left(x=L_{e} / 3\right)=\Delta U_{x k}^{1}\right.$ and $U\left(x=2 L_{e} / 3\right)=$ $\Delta U_{x k}^{2}$ ), see Figure 15 for more clarification : 


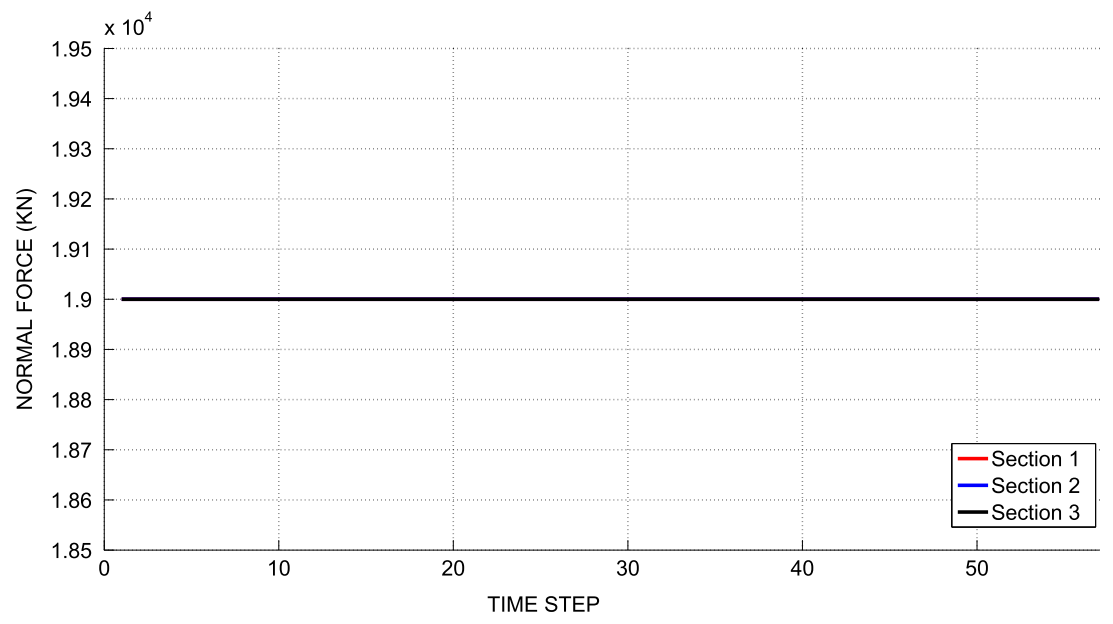

Figure 16. A simple elastic perfectly plastic Timoshenko beam subjected to a rotation and an axial force - Normal force at the 3 sections within the first element for the enhanced FCQ formulation.

$$
U_{x}=\left[\begin{array}{llll}
N_{x i} & N_{x k}^{1} & N_{x k}^{2} & N_{x j}
\end{array}\right]\left[\begin{array}{c}
U_{x i} \\
\Delta U_{x k}^{1} \\
\Delta U_{x k}^{2} \\
U_{x j}
\end{array}\right],
$$

with

$$
\begin{aligned}
& N_{x i}=-\frac{9}{2}\left(\frac{x}{L_{e}}\right)^{3}+9\left(\frac{x}{L_{e}}\right)^{2}-\frac{11}{2} \frac{x}{L_{e}}+1 ; N_{x j}=\frac{9}{2}\left(\frac{x}{L_{e}}\right)^{3}-\frac{9}{2}\left(\frac{x}{L_{e}}\right)^{2}+\frac{x}{L_{e}} ; \\
& N_{x k}^{1}=\frac{27}{2}\left(\frac{x}{L_{e}}\right)^{3}-\frac{45}{2}\left(\frac{x}{L_{e}}\right)^{2}+9 \frac{x}{L_{e}} ; \quad N_{x k}^{2}=-\frac{27}{2}\left(\frac{x}{L_{e}}\right)^{3}+18\left(\frac{x}{L_{e}}\right)^{2}-\frac{9}{2} \frac{x}{L_{e}} ;
\end{aligned}
$$

where $\Delta U_{x k}^{1}$ and $\Delta U_{x k}^{2}$ are the additional internal degrees of freedom that as before can solved at the global or at the element level (static condensation). Figure 16 depicts the response of the enhanced FCQ formulation for the previous example using only two elements. It is obvious that the non linear axial-bending interactions are now better reproduced.

\section{Conclusion}

In this paper, a comparison between three different Timoshenko multi-fiber beam formulations was presented: the FLI formulation with linear shape functions, the FCQM formulation with higher order shape functions dependent on the material properties and the FCQ formulation with higher order shape functions and additional internal degrees of freedom. Numerical examples showed that the FLI formulation does not provide accurate results when only one element is adopted. Results are however improved using a finer discretisation. The FCQM formulation is not suitable for non linear calculations but its performance is excellent for elastic linear cases. Finally, the FCQ formulation provides the best results with the smaller number of finite elements. In the end, a novel kinematic enhancement of the axial displacement field of the FCQ element is proposed, in order to increase its ability to simulate non linear axial-bending problems. Further applications are 
necessary to study the performance of the multi-fiber Timosehnko beams for non linear axialshear-bending interactions. The authors are currently working on improving the multi-fiber Timoshenko FCQ beam introducing the embedded discontinuity approach at the sectional and fiber level to better reproduce failure of reinforced concrete structure.

\section{Acknowledgements}

The authors would like to thank the PIA-SINAPS@ project (Sésisme et Installation Nucléaire: Améliorer et Pérenniser la Sureté), approved and funded by the National Agency of Research (ANR) following the RSNR 2012 call for projects on future investments post-Fukoshima. (SINAPS@ ANR11-RSNR-0022).

\section{Disclosure statement}

No potential conflict of interest was reported by the authors.

\section{Funding}

This work was support by National Agency of Research (ANR) following the RSNR 2012 call for projects on future investments post-Fukoshima [SINAPS@ ANR-11-RSNR-0022].

\section{References}

Armero, F., \& Ehrlich, D. (2004). An analysis of strain localization and wave propagation in plastic models of beams at failure. Computer Methods in Applied Mechanics and Engineering, 193, 3129-3171.

Association française de normalisation (French Association for Standardization). 2004. Eurocode 2: Desing of concrete structure. Saint-Denis La Plaine : AFNOR, cop. 2004, 2-12-130641-2, France.

Bairan Garcia, J. M., \& Mari Bernat, A. R. (2006). Coupled model for the non-linear analysis of anisotropic sections subjected to general 3D loading. Part 1: Theoretical Formulation, Computers and Structures, 84, 2254-2263.

Bathe, K.-J. (1996). Finite element procedures. Upper Saddle River, New Jersey 07458: Prentice Hall.

Bažant, Z. P., Pan, J., \& PijaudierCabot, G. (1987). Softening in Reinforced Concrete Beams and Frames. Journal of Structural Engineering, 113, 2333-2347. doi: 10.1061/(ASCE)0733-9445(1987) 113:12(2333)

Beirão da Veiga, L., Lovadina, C., \& Reali, A. (2012). Avoiding shear locking for the Timoshenko beam problem via isogeometric collocation methods. Computer Methods in Applied Mechanics and Engineering, 241-244, 38-51. doi:10.1016/j.cma.2012.05.020

Bitar, I. (2013). Un nouvel élément fini poutre pour la modélisation des structures sous sollicitations complexes [New Finite Element beam for structure modeling under complex loading] (Master's thesis). École Centrale de Nantes.

Bui, N. N., Ngo, M., Nikolic, M., Brancherie, D., \& Ibrahimbegović, A. (2014). Enriched Timoshenko beam finite element for modeling bending and shear failure of reinforced concrete frames. Computers \& Structures, 143, 9-18. doi:10.1016/j.compstruc.2014.06.004

Caillerie, D., Kotronis, P., \& Cybulski, R. (2015). A Timoshenko finite element straight beam with internal degrees of freedom. International Journal for Numerical and Analytical Methods in Geomechanics, 39, 1753-1773. doi:10.1002/nag

Casaux, G. (2003). Modélisation tridimensionnelle du comportement sismique d'ouvrages en béton armé: développement de méthodes simplifiées [3D modeling of the seismic behavior of reinforced concrete structures: development of simplified methods] (Ph.D. thesis). Cachan, École normale supérieure. 
Casaux-Ginestet, G., \& Ibrahimbegovic, A. (2011). On multi-fiber beam model with coupled axial and bending response. European Journal of Computational Mechanics/Revue Européenne de Mécanique Numérique, 20, 411-426.

Ceresa, P., Petrini, L., \& Pinho, R. (2007). Flexure-shear fiber beam-column elements for modeling frame structures under seismic loading state of the art. Journal of Earthquake Engineering, 11 (sup1), 46-88.

Ceresa, P., Petrini, L., Pinho, R., \& Sousa, R. (2009). A fibre flexure-shear model for seismic analysis of RC-framed structures. Earthquake Engineering \& Structural Dynamics, 38, 565586. doi:10.1002/eqe

Chambon, R., Caillerie, D., \& Matsuchima, T. (2001). Plastic continuum with microstructure, local second gradient theories for geomaterials: Localization studies. International Journal of Solids and Structures, 38, 8503-8527. doi:10.1016/S0020-7683(01)00057-9

Chan, E. C.-Y. (1983). Nonlinear geometric, material and time dependent analysis of reinforced concrete shells with edge beams (Ph.D. thesis). University of California, Berkeley.

Ciampi, V., \& Carlesimo, L. (1986). A nonlinear beam element for seismic analysis of structures. 8th European Conference on Earthquake Engineering, 73-76.

Coleman, J., \& Spacone, E. (2001). Localization issues in force-based frame elements. Journal of Structural Engineering, 127, 1257-1265.

Cowper, G. (1966). The shear coefficient in Timoshenko's beam theory. Journal of Applied Mechanics, $33,335-340$.

Crisfield, M. A. (1991). Nonlinear finite element analysis of solids and structures (Vol. 1). New York, NY: Essentials, Wiley.

De Ville de Goyet, V. (1989). L'analyse statique non linéaire par la méthode des éléments finis des structures spatiales formées de poutres à section non symétrique [Non linear static analysis by the Finite Element method of spatial structures formed of non-symmetrical section beams] (Ph.D. thesis). Université de Liège.

Desprez, C., Kotronis, P., \& Mazars, J. (2014). Seismic vulnerability assessment of a RC structure before and after FRP retrofitting. Bulletin of Earthquake Engineering, 1-26. doi:10.1007/s10518-014-9621-1

Desprez, C., Mazars, J., Kotronis, P., \& Paultre, P. (2013). Damage model for FRPconfined concrete columns under cyclic loading. Engineering Structures, 48, 519-531. doi:10.1016/j.engstruct.2012.09.019

Donea, J., \& Lamain, L. (1987). A modified representation of transverse shear in $C^{0}$ quadrilateral plate elements. Computer Methods in Applied Mechanics and Engineering, 63, 183-207.

Dong, S. B., Alpdogan, C., \& Taciroglu, E. (2010). Much ado about shear correction factors in Timoshenko beam theory. International Journal of Solids and Structures, 47, 1651-1665. doi:10.1016/j.ijsolstr.2010.02.018

Dujc, J., Brank, B., \& Ibrahimbegovic, A. (2010). Multi-scale computational model for failure analysis of metal frames that includes softening and local buckling. Computer Methods in Applied Mechanics and Engineering, 199, 1371-1385. doi:10.1016/j.cma.2009.09.003

Friedman, Z., \& Kosmatka, J. B. (1993). An improved two-node Timoshenko beam finite element. Computers \& Structures, 47, 473-481.

Grange, S., Botrugno, L., Kotronis, P., \& Tamagnini, C. (2011). The effects of soil - structure interaction on a reinforced concrete viaduct. Earthquake Engineering \& Structural Dynamics, 40, 93-105. doi:10.1002/eqe.1034

Grange, S., Kotronis, P., \& Mazars, J. (2009). Numerical modelling of the seismic behaviour of a 7-story building: NEES benchmark. Materials and Structures, 42, 1433-1442. doi:10.1617/s11527-008-9462-y

Guedes, J., Pegon, P., \& Pinto, A. (1994). A fibre/Timoshenko beam element in Castem 2000. Italy: Special publication Nr. I.94.31, Applied Mechanics Unit, Institute for Safety Technology, Joint Research Centre, Commission of the European Communities, I-21020 ISPRA (VA). 
Ibrahimbegovic, A., \& Frey, F. (1993). Finite element analysis of linear and non-linear planar deformations of elastic initially curved beams. International Journal for Numerical Methods in Engineering, 36, 3239-3258.

Ibrahimbegovic, A., Jehel, P., \& Davenne, L. (2007). Coupled damage-plasticity constitutive model and direct stress interpolation. Computational Mechanics, 421, 1-11. doi:10.1007/s00466-007-0230-6

Ile, N., Nguyen, X.-H., Kotronis, P., Mazars, J., \& Reynouard, J. M. (2008). Shaking table tests of lightly RC walls: Numerical simulations. Journal of Earthquake Engineering, 12, 849-878. doi:10.1080/13632460801890430

Ile, N., \& Reynouard, J. M. (2000). Nonlinear analysis of reinforced concrete shear wall under earthquake loading. Journal of Earthquake Engineering, 4, 183-213. doi: $10.1142 / \mathrm{S} 1363246900000102$

Izzuddin, B. A. (1990). Nonlinear dynamic analysis of framed structures (Ph.D. thesis). Imperial College London (University of London).

Jukić, M., Brank, B., \& Ibrahimbegovic, A. (2013). Embedded discontinuity finite element formulation for failure analysis of planar reinforced concrete beams and frames. Engineering Structures, 50, 115-125. doi:10.1016/j.engstruct.2012.07.028

Jukić, M., Brank, B., \& Ibrahimbegović, A. (2014). Failure analysis of reinforced concrete frames by beam finite element that combines damage, plasticity and embedded discontinuity. Engineering Structures, 75, 507-527. doi:10.1016/j.engstruct.2014.06.017

Kiendl, J., Auricchio, F., Hughes, T. J. R., \& Reali, A. (2015). Single-variable formulations and isogeometric discretizations for shear deformable beams. Computer Methods in Applied Mechanics and Engineering, 284, 988-1004. doi:10.1016/j.cma.2014.11.011

Kotronis, P., \& Mazars, J. (2005). Simplified modelling strategies to simulate the dynamic behaviour of R/C walls. Journal of Earthquake Engineering, 9, 285-306. doi:10.1142/S1363246905001979

Kotronis, P., Ragueneau, F., \& Mazars, J. (2005). A simplified modelling strategy for R/C walls satisfying PS92 and EC8 design. Engineering Structures, 27, 1197-1208. doi:10.1016/j.engstruct.2005.03.003

Litewka, P., \& Rakowski, J. (1998). The exact thick arch finite element. Computers and Structures, 68, 369-379. doi:10.1016/S0045-7949(98)00051-0

Marini, A., \& Spacone, E. (2006). Analysis of reinforced concrete elements including shear effects. ACI Structural Journal, 103, 645-655.

Mazars, J., Kotronis, P., \& Davenne, L. (2002). A new modelling strategy for the behaviour of shear walls under dynamic loading. Earthquake Engineering \& Structural Dynamics, 31, 937-954. doi:10.1002/eqe.131

Mazars, J., Kotronis, P., Ragueneau, F., \& Casaux, G. (2006). Using multifiber beams to account for shear and torsion: Applications to concrete structural elements. Computer Methods in Applied Mechanics and Engineering, 195, 7264-7281. doi:10.1016/j.cma.2005.05.053

Mukherjee, S., Reddy, J. N., \& Krishnamoorthy, C. S. (2001). Convergence properties and derivative extraction of the superconvergent Timoshenko beam finite element. Computer Methods in Applied Mechanics and Engineering, 190, 3475-3500. doi:10.1016/S0045-7825(00)00280-2

Navarro Gregori, J., Miguel Sosa, P., Fernandez Prada, M. A., \& Filippou, F. C. (2007). A3D numerical model for reinforced and prestressed concrete elements subjected to combined axial, bending, shear and torsion loading. Engineering Structures, 29, 3404-3419.

Needleman, A. (1988). Material rate dependence and mesh sensitivity in localization problems. Computer Methods in Applied Mechanics and Engineering, 67, 69-85. doi:10.1016/0045-7825(88)90069-2

Nickel, R., \& Secor, G. (1972). Convergence of consistently derived Timoshenko beam finite elements. International Journal for Numerical Methods in Engineering, 5, 243-252.

Owen, D. R., \& Hinton, E. (1980). Finite elements in plasticity (Vol. 271). Swansea: Pineridge Press.

Papa Dukić, E., Jelenić, G., \& Gaceša, M. (2014). Configuration-dependent interpolation in higher-order 2D beam finite elements. Finite Elements in Analysis and Design, 78, 47-61. doi:10.1016/j.finel.2013.10.001 
Pegon, P. (1994). A Timoshenko simple beam element in Castem 2000, Special publication Nr. I.94.04. Italy: Applied Mechanics Unit, Institute for Safety Technology, Joint Research Centre, Commission of the European Communities, I-21020 ISPRA (VA).

Petrangeli, M., Pinto, P. E., \& Ciampi, V. (1999). Fiber element for cyclic bending and shear of RC structures. I: Theory. Journal of Engineering Mechanics, 125, 994-1001.

Pham, B. H., Brancherie, D., Davenne, L., \& Ibrahimbegović, A. (2012). Stress-resultant models for ultimate load design of reinforced concrete frames and multi-scale parameter estimates. Computational Mechanics, 51, 347-360. doi:10.1007/s00466-012-0734-6

Pham, B. H, Davenne, L., Brancherie, D., \& Ibrahimbegović, A. (2010). Stress resultant model for ultimate load design of reinforced-concrete frames: Combined axial force and bending moment. Computers \& concrete, 7, 303-315. doi:10.12989/cac.2010.7.4.303

Pinho, R., \& Elnashai, A. (2000). Dynamic collapse testing of a full-scale four storey RC frame. ISET Journal of earthquake Technology, 37, 143-163.

Rakowski, J. (1990). The interpretation of the shear locking in beam elements. Computers and Structures, 37, 769-776. doi:10.1016/0045-7949(90)90106-C

Ranzo, G., \& Petrangeli, M. (1988). A fibre finite beam element with section shear modelling for seismic analysis of RC structures. Journal of Earthquake Engineering, 2, 443-447.

Reddy, J. N. (1997). On locking-free shear deformable beam finite elements. Computer Methods in Applied Mechanics and Engineering, 7825, 113-132. doi:10.1016/S0045-7825(97)00075-3

Saritas, A., \& Filippou, F. C. (2009). Inelastic axial-flexure-shear coupling in a mixed formulation beam finite element. International Journal of Non-Linear Mechanics, 44, 913-922.

Scordelis, A. C. (1984). Computer models for nonlinear analysis of reinforced and prestressed concrete structures. PCI Journal, 29, 116-135.

Šćulac, P., Jelenić, G., \& Škec, L. (2014). Kinematics of layered reinforced-concrete planar beam finite elements with embedded transversal cracking. International Journal of Solids and Structures, 51, 74-92. doi:10.1016/j.ijsolstr.2013.09.011

Simo, J., \& Hughes, T. (1998). Computational inelasticity. New York: Springer.

Simo, J. C., Oliver, J., \& Armero, F. (1993). An analysis of strong discontinuities induced by strain-softening in rate-independent inelastic solids. Computational Mechanics, 12, 277-296. doi:10.1007/BF00372173

Spacone, E., Filippou, F. C., \& Taucer, F. F. (1996). Fibre beam-column model for non-linear analysis of R/C frames: Part I. formulation. Earthquake Engineering and Structural Dynamics, 25, 711726.

Spacone, E., \& Limkatanyu, S. (2000). Response of RC members including bond-slip effects. ACI Structural Journal, 6, 831-839.

Stolarski, H. \& Belytschko, T. (1982). Membrane locking and reduced integration for curved elements. Journal of Applied Mechanics, 49, 172-176.

Tessler, A., \& Dong, S. (1981). On a hierarchy of conforming Timoshenko beam elements. Computers \& Structures, 14, 335-344.

Thomas, J., \& Abbas, B. (1975). Finite element model for dynamic analysis of Timoshenko beam. Journal of Sound and Vibration, 41, 291-299.

Timoshenko, S. P. (1921). On the correction for shear of the differential equation for transverse vibrations of prismatic bars. The London, Edinburgh, and Dublin Philosophical Magazine and Journal of Science, 41, 744-746.

Tong, P., \& Pian, T. H. (1969). A variational principle and the convergence of a finite-element method based on assumed stress distribution. International Journal of Solids and Structures, 5, 463-472.

Vecchio, F. J., \& Collins, M. P. (1986). The modified compression-field theory for reinforced concrete elements subjected to shear. ACI Journal Proceedings, 83, 219-231. doi:10.14359/10416

Vecchio, F. J., \& Collins, M. P. (1988). Predicting the response of reinforced concrete beams subjected to shear using modified compression field theory. ACI Structural Journal, 85, 258268. doi: $10.14359 / 2515$

Xu, S. Y., \& Zhang, J. (2012). Axial-shear-flexure interaction hysteretic model for RC columns under combined actions. Engineering Structures, 34, 548-563. doi:10.1016/j.engstruct.2011.10.023 
Yunhua, L. (1998). Explanation and elimination of shear locking and membrane locking with field consistence approach. Computer Methods in Applied Mechanics and Engineering, 162, 249-269. doi:10.1016/S0045-7825(97)00346-0

Zienkiewicz, O. C., \& Taylor, R. L. (2000). The finite element method: The basics (Vol. 1). Oxford: Butterworth-heinemann.

Zona, A., \& Ranzi, G. (2011). Finite element models for nonlinear analysis of steelconcrete composite beams with partial interaction in combined bending and shear. Finite Elements in Analysis and Design, 47, 98-118. doi:10.1016/j.finel.2010.09.006 